\title{
The Fate of Incoming HSV-1 Genomes Entering the Nucleus
}

\author{
Oren Kobiler* and Amichay Afriat
}

Department of Clinical Microbiology and Immunology, Sackler School of Medicine, Tel Aviv University, Tel Aviv, Israel

*okobiler@tauex.tau.ac.il

DOI: https://doi.org/10.21775/cimb.041.221

\begin{abstract}
Herpesvirus genomes enter the eukaryotic nucleus as large linear double stranded DNA molecules that are free of any proteins (naked DNA). Once inside the nucleus, the HSV-1 genomes immediately associate with proteins that will be instrumental in the organization and regulation of these genomes. These initial interactions are thought to determine the fate of the infecting genomes. In general, the host cell has evolved several mechanisms to suppress viral genomes and induce latent or abortive infections. On the other hand, the virus has evolved to use viral and cellular factors to promote lytic infection. Recent findings suggest that not all viral genomes in the infected nucleus will develop progeny and that not all genetically identical cells will support successful virus propagation. Thus, the decision between different fates of infection is determined at both single-cell and single-genome levels. Here we summarize current knowledge on the conditions and interactions that lead to each outcome and discuss the unknown determinants.
\end{abstract}




\section{Introduction}

The entry of herpesviruses into cells can be divided into two major steps: capsid release into the cytoplasm and injection of viral genomes into the nucleoplasm. The fusion of the viral membrane with the host membrane releases the viral capsid into the cytoplasm together with a set of proteins found in the viral tegument layer. The inner tegument proteins remain associated with the capsid and mediate its movement in the cytoplasm. Viral outer tegument proteins (like VHS and VP16) as well as host proteins that are found in the tegument (like DDX3X and MIF) are thought to facilitate viral infection by modulating host signaling and host and viral gene expression (Kwong and Frenkel, 1987; Kwong et al., 1988; Weinheimer et al., 1992; Kelly et al., 2009; Stegen et al., 2013). Viral genomes are released from the viral capsids into the nucleus through nuclear pore complexes as large linear double stranded DNA molecules (Ojala et al., 2000; Pasdeloup et al., 2009). The viral genome enters the nucleus as a naked DNA molecule and starts to associate with proteins once within the nucleoplasm.

The eukaryotic nucleus has a highly ordered structure, with chromosomal territories, nucleolus and other specific sites for different tasks (Lanctot et al., 2007). Furthermore, the eukaryotic genome is bound to histones and is condensed into an ordered, compact structure. The positioning and condensation level of the genome correlate with gene activity (Sexton and Cavalli, 2015). During herpesviruses infection, insertion of large naked viral DNA (vDNA) into the host nucleus results in significant disturbance to this order. As all other mammalian dsDNA viruses enter the nucleus associated with histones or histone like proteins, herpesviruses nuclear entry is probably the only natural scenario in which mammalian nuclei encounter such a major event. Since herpesviruses are ubiquitous and ancient viruses that have probably co-evolved with their hosts before mammalian lineages appeared (McGeoch et al., 2006), it is not surprising that the host nucleus has developed many mechanisms to counteract invasion of these large genomes. Thus, an arms race between these viruses and their hosts has been going on for 
millions of years, and a major battleground of this conflict is within the host cell nucleus.

The host defense against viral pathogens can be divided to three major immune arms: intrinsic, innate and adaptive. These arms cooperate and overlap to fight off invading pathogens. The first line of intra-nuclear defense against DNA virus infection (i.e., the intrinsic immunity) is coordinated by a set of constitutively expressed host-cell restriction factors (reviewed in (Everett, 2013; Komatsu et al., 2016)). In this review, we will focus on mechanisms of the first line of defense. Herpesviruses have evolved mechanisms to avoid these host defenses. Since these viral strategies are highly efficient, mutation of the viral counteracting factors is often required to reveal the host defense mechanisms. In the case of HSV-1, many of the host intrinsic immune mechanisms were identified by using viral strains deleted or mutated in the ICP0 gene (Boutell and Everett, 2013).

Herpesvirus/host interactions that take place in the nucleus have been studied for several decades and were recently expanded upon with the improvement of available technology. For example, combining the ability to detect incoming viral genomes by incorporating biorthogonal traceable precursors into the viral genomes [e.g., ethynyl-deoxyuridine (EdU) or ethynyl-deoxycytidine $(E d C)$ ], together with high-resolution fluorescent microscopy and live cell imaging, allowed better characterization of viral host interactions during critical early stages of the viral genomes in the nucleus (Diner et al., 2016; Sekine et al., 2017; Alandijany et al., 2018; Dembowski and DeLuca, 2018). Furthermore, recent studies at single-cell resolution have identified differences in the infection outcomes among genetically identical cells (Drayman et al., 2017; Sekine et al., 2017; Cohen et al., 2018; Drayman et al., 2019; Wyler et al., 2019; Cohen et al., 2020) shedding further light on these complex interactions.

In this review, we focus on the initial interactions of viral genomes with host and viral factors inside the nucleus that ultimately determine the outcome of infection. Since these interactions are highly complex and usually begin a 
cascade of downstream processes, we try to highlight concepts rather than specific interactions. We have limited our discussion to events prior to formation of replication compartments (RCs), as we assume that once RCs are formed the cell is committed to the lytic cycle.

\section{Possible fates of viral genomes}

Entry of a virus into a permissive and susceptible cell leads to either a productive lytic infection that results in progeny release and cell death, or to an abortive infection, in which the cell survives viral infection without generating new viral particles. In the case of herpesviruses (as well as other viruses), establishment of a latent infection is a third possibility, in which viral genomes remain within the host cell without major changes in cell viability for a relatively long time. From this condition, the virus can reactivate and produce progeny. Recent evidence suggests that latent viral genomes could be detected in cells that survived abortive infection (Cohen et al., 2020). The decision between the different outcomes depends partially on viral factors since some viral mutants predominately favor one outcome (Samaniego et al., 1998; Marshall et al., 2000). But, the decision is also determined by host factors. For example, infection with HSV-1 results in lytic infection for most cell types; however, among myeloid cells, only specific types support lytic infection (Linnavuori and Hovi, 1983; Leary et al., 1985; Shivkumar et al., 2016).

During lytic infection viral genomes enter the nucleus and initiate a cascade of viral gene expression. First, the tegument protein VP16 (encoded by the UL48 gene) forms a complex with host transcription activators and induces expression of the immediate early (IE) viral genes (Wysocka and Herr, 2003), which are defined as genes expressed prior to viral protein synthesis (Honess and Roizman, 1974, 1975). The IE proteins regulate expression of early and late genes. Early genes are mostly involved in viral replication (Wu et al., 1988; Muylaert et al., 2011), which takes place in specific sites in the nucleus known as replication compartments (Quinlan et al., 1984; de Bruyn Kops and Knipe, 1988; Kobiler and Weitzman, 2019). The late genes, which are expressed following viral replication (Dremel and DeLuca, 2019a), are mostly structural 
genes required for assembly of new progeny viruses (Honess and Roizman, $1974,1975)$. The release of progeny viruses from infected cells eventually leads to cell death. This is thought to be the default process in most infected cells, especially in non-neuronal cells and in tissue culture.

For alphaherpesviruses, clinical and experimental evidence suggested that latency occurs spontaneously only in peripheral sensory neurons or neurons of the autonomic sympathetic ganglia. Moreover, latency is also host specific, i.e., spontaneous latency occurs almost exclusively in the natural host of the virus (Koyuncu et al., 2018). Thus, it seems that latent infection can only take place under special circumstances. However, quiescent infections that resemble latency can be observed in abortively infected non-neuronal cells (Cohen et al., 2020). In vitro, neuronal and non-neuronal cells can be induced into a latencylike state by different methods that inhibit viral replication (O'Neill, 1977; Russell and Preston, 1986; Scheck et al., 1986; Shiraki and Rapp, 1986; Harris and Preston, 1991; McMahon and Walsh, 2008; Edwards and Bloom, 2019; Hu et al., 2020). During latency, the viral genomes are found as episomes (independently maintained, circular vDNA molecules) inside the host nucleus. These genomes are tightly associated with host histones that maintain genomes in the heterochromatin state, which prevents formation of new viral particles (Deshmane and Fraser, 1989; Wang et al., 2005; Cliffe et al., 2009; Kwiatkowski et al., 2009). Limited viral gene expression as well as expression of latency-associated RNAs (LAT RNAs) can be detected during latency (Ma et al., 2014). The most important characteristic of this condition is the ability to reactivate and generate new viral particles. Many stress signals can induce these viral genomes to reactivate (Suzich and Cliffe, 2018).

Abortive infection is defined as an infection in which viruses enter the cell and some viral elements are generated; however, no progeny virus is produced (Aurelian and Roizman, 1964, 1965; Roizman and Aurelian, 1965). The abortive infection can result from blocking the lytic process either before or after vDNA replication takes place (Leary et al., 1985). Thus, several distinct mechanisms can lead to abortive infections. Abortive viral genomes may be 
indistinguishable from latent genomes (Cohen et al., 2020), especially in the early stages post infection, and differ only retrospectively by their ability to reactivate. While the mechanism of abortive infection is not defined, in this review we will consider abortive/latent viral genomes as those that enter the nucleus and do not initiate lytic infection.

\section{Early steps in the nucleus}

Initial interactions of viral genomes with viral and host proteins in the nucleus have an important role in determining the fate of infection (Figure 1). Most host proteins that repress gene expression from incoming viral genomes are considered part of nuclear intrinsic immunity. Single-cell analysis suggested that in cells with higher levels of host housekeeping genes, fewer viral genomes can initiate gene expression and replication (Cohen and Kobiler, 2016). Similarly, the number of viral genomes initiating expression is cell-type dependent and is reduced under conditions that increase the levels of intrinsic factors, such as exposing the cells to histone deacetylases inhibitors (Shapira et al., 2016). These results highlight the role of host factors in preventing incoming viral genomes to initiate lytic infection. Viral proteins counteract these intrinsic immunity proteins and stimulate viral gene expression. Viral gene expression correlates with the number of viral genomes that can replicate in individual cells (Cohen and Kobiler, 2016). However, it has not yet been established whether viral gene expression allows more viral genomes to initiate replication. An alternative hypothesis is that replication of multiple viral genomes results in higher levels of gene expression.

In an attempt to characterize the initial virus/host interactions after nuclear entry, there are two major challenges: first, to develop an unbiased method to detect all interactions, and second to analyze these interactions as early as possible after nuclear entry. The first challenge was overcome by pulling down the viral genomes and using mass spectrometry to identify all associated proteins. Most of these studies have been limited to replicating viral genomes (Taylor and Knipe, 2004; Dembowski and DeLuca, 2015; Dembowski et al., 2017; Reyes et al., 2017) as pulldown was carried out by incorporation of EdC 


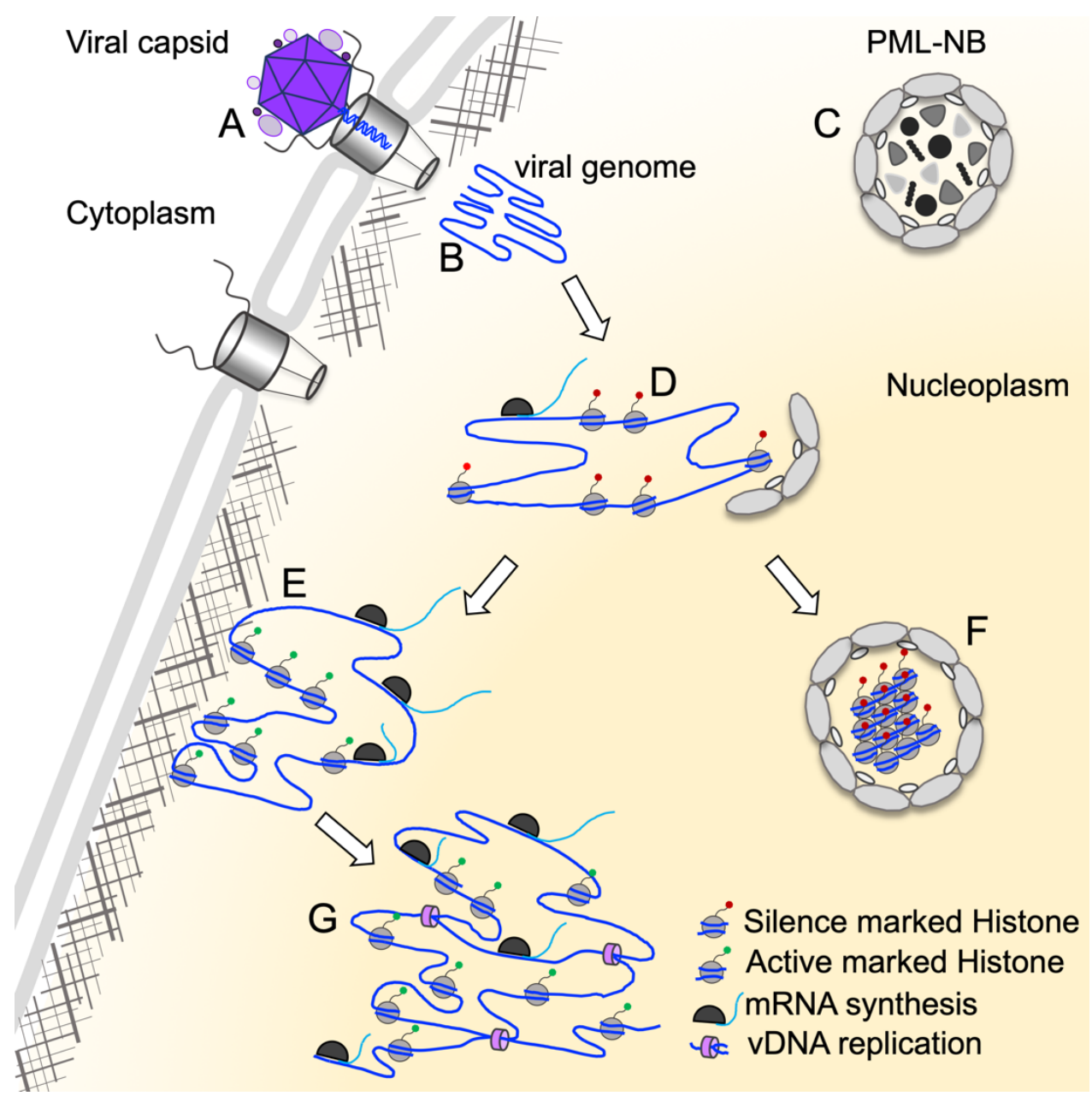

Figure 1. The fates of incoming viral genomes. A schematic illustration of the steps of incoming viral genomes in the nucleus. (A) Capsid docks at the nuclear pore complex (NPC), and viral genome is translocated into the nucleus through the NPC. (B) The naked viral genome enters the nucleus and remains condensed. (C) Promyelocytic Leukemia Nuclear Bodies (PML-NB's) are present near sites of entering genomes. (D) The entering genome becomes circular, binds histones, and initiates IE gene expression while host factors try to repress gene expression. (E) The viral DNA (VDNA) associates with the nuclear lamina where enhanced viral gene expression takes place. $(F)$ vDNA is repressed both by the formation of heterochromatin and by binding of PML proteins. (G) Replication of the VDNA in early RCs. The viral inner tegument and capsid is colored purple, the vDNA is in blue, viral mRNA in light blue and host histones are gray round particles with tails labeled with active (green) and silencing (red) marks. All other host proteins and structures are in different shades of gray. 
to label the vDNA during the DNA replication process. The second challenge was addressed with the ability to generate infectious viral particles containing viral genomes that incorporated EdC/EdU. Once available, this method was used to visualize the incoming genomes with fluorescent microscopy. Sekine et al. detected the first genomes arriving at the nucleus following incubation of the virus at $4^{\circ} \mathrm{C}$ for 45 minutes (to prevent membrane fusion) and then shifting to $37^{\circ} \mathrm{C}$ for 30 minutes (Sekine et al., 2017). Similar labeling method allowed to detect viral genomes in the nucleus as early as 30 minutes after adding virus to cells at $37^{\circ} \mathrm{C}$ (Alandijany et al., 2018). Dembowski et al. identified host proteins associated with incoming viral genomes at different time points prior to replication using mass spectrometry (Dembowski and DeLuca, 2018). In this study, the first time-point analyzed was one hour post infection (hpi), which corresponds to two hours after the virus was first added to the cells at $37^{\circ} \mathrm{C}$. These three papers (Sekine et al., 2017; Alandijany et al., 2018; Dembowski and DeLuca, 2018) used three different methods to initiate infection and determine the initial time of infection. This emphasizes the need for an accepted synchronization method for recognizing initial events of incoming viral genomes (Ralph et al., 2017).

\section{Antiviral defense responses to incoming viral genomes in the nucleus}

The nucleus has evolved several mechanisms to cope with foreign DNA. Since vDNA enters naked into the nucleus, it has been assumed that the first interactors are components of these host defense mechanisms. In the analysis of Dembowski et al., several classes of host proteins were found to be associated with the vDNA, including proteins involved in DNA damage response (DDR), proteins from the Promyelocytic Leukemia Nuclear Body (PML-NB), histones, histone modifiers, transcription factors, and RNA processing proteins (Dembowski and DeLuca, 2018). The DDR, PML-NB and histone modifier proteins, alongside the innate immunity sensors IFI16, cGAS and STING, are considered to be the first line of host defense response to viral genomes (Alandijany, 2019). 


\section{DNA damage response}

The viral genome found inside the capsid typically have several nicks and gaps (Kieff et al., 1971; Frenkel and Roizman, 1972; Sheldrick et al., 1973; Smith et al., 2014). Once the genome is released from the capsid into the nucleus, these DNA breaks and the open ends of the linear naked genome trigger nuclear mechanisms targeting foreign DNA that include components of the DDR pathways and the PML-NB (Smith et al., 2014). Therefore, it is not surprising that the proteins associated with DDR and the PML-NB are among the first host factors to be recruited to the incoming genomes (Lilley et al., 2011; Dembowski and DeLuca, 2018).

Many components of the antiviral DDR pathways are degraded or inhibited by viral infection (reviewed in (Smith and Weller, 2015)). These include proteins involved in classic nonhomologous end joining (Lees-Miller et al., 1996; Parkinson et al., 1999; Trigg et al., 2017), homologous recombination signaling (Lilley et al., 2010), and ATR signaling involved in single strand DNA break repair (Mohni et al., 2010). Sensing of damaged DNA by the DDR system can detect the foreign DNA (especially open-ended DNA containing nicks and gaps) and may initiate a cascade of events to prevent viral gene expression before replication initiates (Lilley et al., 2011). This DNA sensing can stimulate both intrinsic and innate antiviral responses (Trigg and Ferguson, 2015). On the other hand, several of the key regulators of DDR are induced during HSV infection and are required for efficient productive lytic infection (Lilley et al., 2005; Mohni et al., 2011; Mohni et al., 2013; Karttunen et al., 2014; Edwards et al., 2018) likely because viral replication is associated with recombination (Wilkinson and Weller, 2003) and many of DDR proteins can be found in viral RCs (Taylor and Knipe, 2004; Dembowski and DeLuca, 2015; Dembowski et al., 2017; Reyes et al., 2017). Recently, it was suggested that the DDR may have an important role in determining the outcome of the infection (lytic vs. latency) since DDR proteins are not activated in HSV1 infected neurons (Brown, 2017). Thus, the DDR response can both positively and negatively regulate viral infection. 


\section{Promyelocytic Leukemia Nuclear Body}

PML-NBs, also known as nuclear domains 10 (ND10), are proteinaceous nuclear structures that are hubs for many nuclear activities. The PML protein is the key structural protein in the PML-NB assemblies. Several other proteins are also permanent residents of these structures whereas other proteins can be temporarily present under different conditions including different cell types or stresses (Lallemand-Breitenbach and de The, 2018). PML-NBs have been associated with a broad range of cellular functions including apoptosis, DNA repair, epigenetic control, oncogenesis and response to viral infection. It has been suggested that most of these functions are regulated by posttranscriptional modifications, especially by SUMOylation (small ubiquitin-like modifier (Sternsdorf et al., 1997; Muller et al., 1998)).

Incoming HSV-1 genomes rapidly associate with PML-NB (Maul et al., 1996; Everett and Murray, 2005; Alandijany et al., 2018). During wild-type HSV-1 infection, this interaction is transient since the E3 ubiquitin ligase activity of the viral ICPO protein induces degradation and disassembly of PML-NBs (see below). The PML protein itself entraps viral genomes as early as 30 minutes post incubation with cells at $37^{\circ} \mathrm{C}$ (Alandijany et al., 2018). Viral genomes entrapped within PML-NBs can also be found in latent neuronal cells (Catez et al., 2012; Maroui et al., 2016). Therefore, it has been suggested that PML entrapment itself has an inhibitory effect on viral genomes. Other PML-NB proteins that colocalize with the $\mathrm{PML}$ and viral genomes are Daxx (DeathDomain Associated Protein), Sp100 (Speckled Protein of $100 \mathrm{kDa}$ ), and ATRX ( $\alpha$-Thalassemia/Mental Retardation Syndrome X-Linked) (Everett and Murray, 2005; Glass and Everett, 2013; Alandijany et al., 2018). Depletion of each of these proteins by shRNA constructs partially rescues growth defects of HSV-1 deleted for the ICPO gene but has no effect on wild-type HSV-1 replication (Everett et al., 2008; Lukashchuk and Everett, 2010), suggesting a host defense mechanism that is inhibited by the wild-type HSV-1. Daxx and ATRX are known to promote nucleosome assembly and repressive heterochromatin state (Lukashchuk and Everett, 2010). It was further shown that SUMO 
modification pathways are required for recruitment of PML-NB proteins to viral genomes (Cuchet-Lourenco et al., 2011).

While the molecular mechanisms by which PML-NBs regulate expression from viral genomes are not fully understood, it was suggested that the main role of PML-NBs is to enhance chromatin repression of HSV-1 genomes (Gu and Zheng, 2016). One of the mechanisms that repress viral genomes is the histone H3.3 chaperone HIRA, which is relocalized to PML-NBs following viral infection. HIRA deposits variant histone $\mathrm{H} 3.3$ on viral genomes to promote epigenetic silencing of the incoming viral genomes (Rai et al., 2017; Cohen et al., 2018) and also induce the innate immune defenses (McFarlane et al., 2019).

In some cell lines, depletion of the PML protein result in decreased HSV-1 replication (Xu et al., 2016; Xu and Roizman, 2017; Merkl et al., 2018). Thus, similar to the DDR response, PML protein itself or other proteins found in the PML-NBs may also have pro-viral functions (Xu et al., 2016; Xu and Roizman, 2017; Merkl et al., 2018).

\section{Histones and histone modifiers}

Histones do not only function to condense DNA into packaged chromatin but are also master facilitators of transcription and DNA replication. This is achieved by a large array of post-translational modifications on histones regulated by proteins that function as writers, erasers and readers (recently reviewed (Biswas and Rao, 2018)). Writers are proteins that add modifications on the histones (for example, P300 is an histone acetyltransferase), erasers are proteins that remove the modification (such as histone deacetylases, HDACs) and readers are the proteins that recognize the modifications and bind to them (for example, BRD4 that recognize acetylated histones).

Although HSV-1 genomes enter cells as naked DNA molecules, they rapidly associate with histones. These interactions can be detected in cells entering either lytic or latent infection (Deshmane and Fraser, 1989; Herrera and 
Triezenberg, 2004; Kent et al., 2004; Kubat et al., 2004; Wang et al., 2005; Huang et al., 2006; Oh and Fraser, 2008; Silva et al., 2008; Cliffe et al., 2009; Lacasse and Schang, 2012). Initially, viral genomes are associated with histones marked with known post-translational modifications correlating with genome silencing, such as histone 3 methylation on lysine 9 and 27 (H3K9me3 and H3K27me3). This suggests that the host utilizes these mechanisms to silence the incoming genomes (Narayanan et al., 2007; Silva et al., 2008; Liang et al., 2009; Lee et al., 2016). Indeed, during latency, viral genomes are maintained in a heterochromatin state with repressed viral gene expression (Deshmane and Fraser, 1989; Wang et al., 2005; Cliffe et al., 2009; Kwiatkowski et al., 2009).

To promote lytic infection, host enzymes directed by viral proteins rapidly remove these silencing marks and install new modification marks that enhance viral gene expression (Liang et al., 2009; Lee et al., 2016). Throughout Iytic infection, the nucleosomes are unstable on viral genomes (Lacasse and Schang, 2010, 2012). Recent findings showed that early during lytic infection the majority of viral genomes are found in condensed chromatin structures that are likely to be inaccessible to transcription and replication (Hu et al., 2019). These results suggest that most incoming viral genomes remain silenced and condensed by nucleosome structures throughout the lytic infection, and that only few genomes need to escape the silencing to initiate active replication.

\section{Viral proteins overcome host defenses}

Many viral genes are required to complete the replication cycle of HSV-1. However, only three proteins (VP16, ICP0 and ICP4) are thought of as the master regulators that determine the fate of infection (Figure 2). All three proteins have been shown to associate with viral genomes at early time points post-nuclear entry and contribute to lytic infection (Gibeault et al., 2016; Dembowski and DeLuca, 2018). 


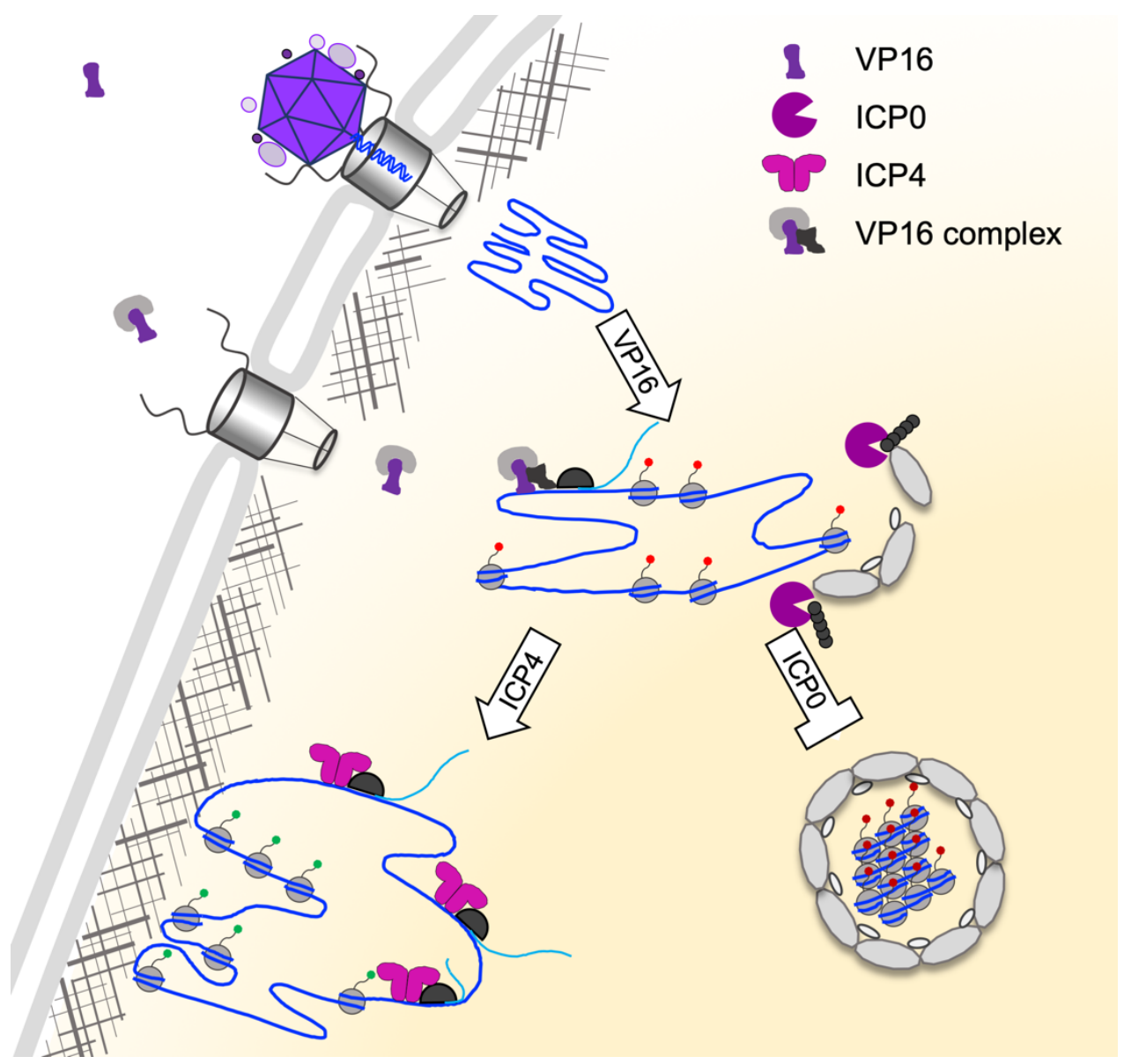

Figure 2. Role of VP16, ICPO and ICP4 in initial steps of infection. The viral proteins VP16, ICP0 and ICP4 are indicated. VP16 is released from the outer tegument into the cytoplasm, where it interacts with the host transcription factor HCF-1 that facilitates entry into the nucleus. VP16 in complex with the host transcription factors Oct-1 and HCF-1 binds to the promoter regions of the IE genes on viral genomes and initiates their transcription. ICPO prevents repression of viral genomes mainly by ubiquitinating host proteins involved in silencing and targeting these proteins to degradation. ICP4 induces expression of early genes that will allow formation of active RCs. All host and viral structures are presented in Figure 1. 
Viral Protein 16 (VP16)

VP16, encoded by the UL48 gene, is a 490-amino-acids protein located in the outer layer of the viral tegument. The protein is conserved across all alphaherpesviruses and has a central core domain and a C-terminal transcriptional activation domain (TAD) (Hirai et al., 2010) (Figure 3A). VP16 binds both HCF-1 and Oct-1 through its core domain to form the VP16 complex which binds vDNA and induce transcription. An individual virion has 500-1000 copies of VP16 (Wysocka and Herr, 2003). Interestingly, the number of VP16 copies per virion varies significantly compared to other tegument proteins, and VP16 levels correlate with infectivity (El Bilali et al., 2017).

When the viral membrane fuses with the cellular membrane during entry, VP16, together with other tegument proteins, is released to the cytoplasm. In the cytoplasm, VP16 binds the host cell factor 1 (HCF-1). HCF-1, is a modular recruiter of chromatin remodeling proteins from different families. It is known to suppress or promote transcription of various genes related to cell-cycle and proliferation depending on the identity of the histone modifier it recruits (Hancock et al., 2010; Zargar and Tyagi, 2012; Oh et al., 2014).

VP16 translocation into the nucleus is facilitated by the nuclear localization signal (NLS) of HCF-1 (La Boissiere et al., 1999). Once in the nucleus, VP16 and HCF-1 bind Oct-1 and form the VP16 complex. Oct-1 is a versatile transcription factor, with promiscuous DNA binding and a plethora of co-factors. Its multifunctional nature owes to the presence of a POU domain, a highly conserved bipartite DNA-binding domain (Herr and Cleary, 1995). VP16 binds the POU domain of Oct-1 in a manner that suggests species-specific host virus recognition (Kristie et al., 1989; Stern et al., 1989).

The VP16 complex, via Oct-1, binds the regulatory element of the viral IE promoter TAATGARAT (where R=purine) (Misra et al., 1996). Additional binding of VP16 to the adjacent DNA near the Oct-1 binding site was also shown to be important for the formation of the VP16 complex (Babb et al., 2001). In addition, VP16 complex binds various gene regulators via the VP16's 

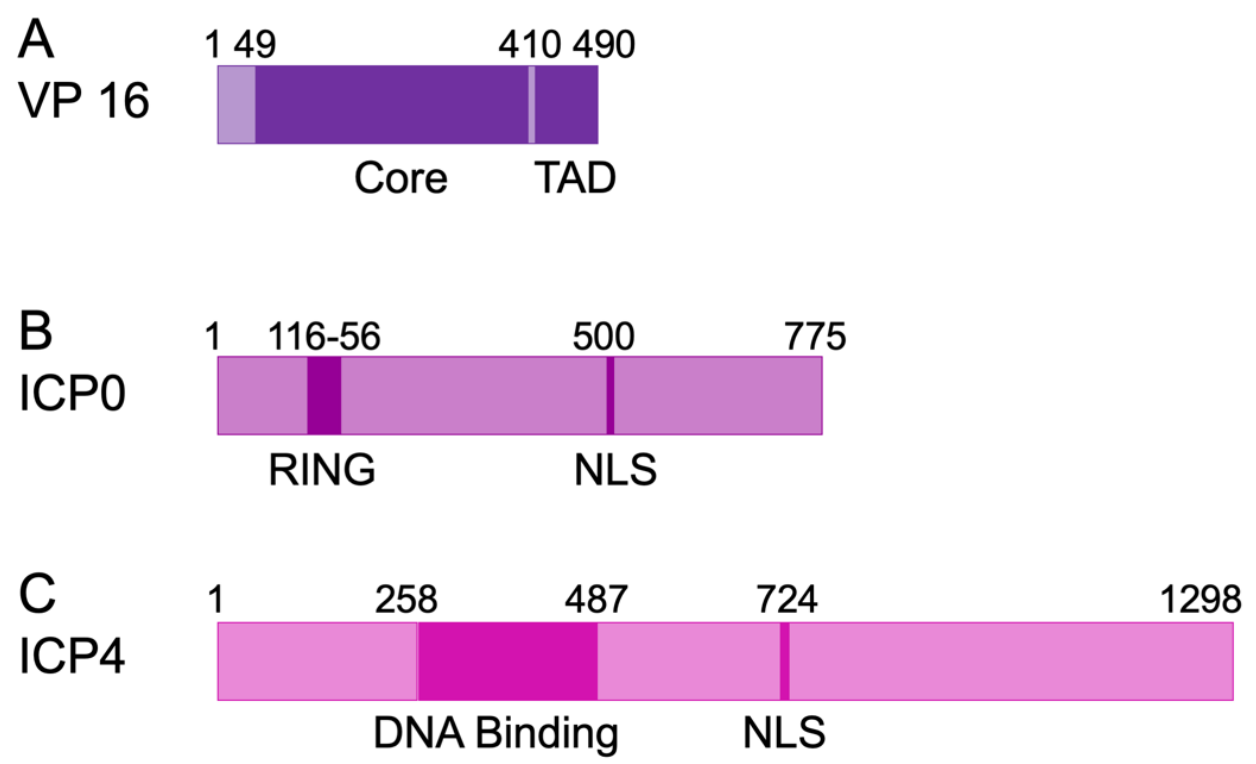

Figure 3. VP16, ICP0 and ICP4 functional domains. Schematic representation of the viral proteins: (A) VP16, (B) ICP0 and (C) ICP4. Functional domains are marked in darker shades and labeled. Sites are numbered according to the amino acid residues.

TAD. The TAD is known to bind histone acetyltransferases, basal transcription factors, histone modifiers and the Mediator complex (Suk and Knipe, 2015). Thus, the VP16 complex and its co-activators are a major driving force in the initiation of viral DNA transcription. Deletion of the VP16 reading frame in HSV-1 inhibits the virus ability to produce viable progeny and causes major defects in the assembly of viral particles (Weinheimer et al., 1992). Mutations in either Oct-1 or HCF-1 binding sites of VP16 or genetic tempering with its TAD results in reduced IE transcription (Smiley and Duncan, 1997; Ottosen et al., 2006).

Successful activation and transcription of IE genes is crucial in determining the genome fate. Decreased activity of VP16 complex often precludes productive infection (Steiner et al., 1990). Initiation of viral gene expression by VP16 is 
widely viewed as a crucial step in the establishment of lytic infection. Furthermore, since VP16 enhances IE gene expression, it regulates expression of the other major viral regulators: ICP0 and ICP4.

\section{Infected Cell Protein 0 (ICPO)}

The 775-amino-acid long IE protein ICPO is encoded by two copies of the RL2 gene found in the long repeat region of the HSV genome (Wadsworth et al., 1975). The ICPO gene is one of the very few HSV genes that contain introns. The introns of ICP0, 765 and 136 nucleotides in size, have not been shown to have any significant role in productive lytic infection or during reactivation (Perry et al., 1986; Natarajan et al., 1991; Lium et al., 1998).

ICPO is not essential for viral replication. Viral strains without functional ICPO protein can initiate replication only at high multiplicity of infection (MOI) (Stow and Stow, 1986; Sacks and Schaffer, 1987). Interestingly, this effect is cell-type dependent, i.e., the relative efficiency of plating between the mutant and wild type strain can range from 1:1000 in human fibroblast to 1:1 in the U2OS cell line derived from osteosarcoma cells (Boutell and Everett, 2013).

One of the major features of ICPO is the zinc-containing RING (really interesting new gene) finger domain positioned in the middle exon (Everett, 1988; Everett et al., 1993; Lium and Silverstein, 1997) (Figure 3B). This domain functions as a E3 ubiquitin ligase that targets several host defense proteins for degradation (reviewed at (Boutell and Everett, 2013)). Since ICP0 was shown to autoubiquitinate in vitro and is subject to proteasome-dependent degradation (albeit not exclusively), it may suggest that ICPO has functional ubiquitination sites (Canning et al., 2004).

ICPO contains a short NLS of seven amino acids within its third exon. Following nuclear entry, ICPO rapidly localizes to PML-NBs. This localization requires the RING finger domain. The close interaction with PML-NBs allows for a swift and effective proteasomal degradation of several proteins that are located in the PML-NBs, including all PML isoforms and some sp100 isoforms (e.g., SUMO 
modified) (Boutell et al., 2011). This degradation is mediated by ubiquitination through the E3 ligase activity of ICPO (Chelbi-Alix and de The, 1999). This ICPO activity leads to the dispersal of PML-NBs and minimizes the intrinsic antiviral response. Depletion of PML can allow a null-ICP0 mutant to achieve high progeny titers, similar to those of a WT virus, a phenotype that can be reversed with reintroduction of some PML isoforms (Cuchet et al., 2011).

Most targets of the E3 activity of ICPO are multifunctional host proteins involved in other defense mechanisms, including DNA damage response (DNA-PK catalytic subunit (Lees-Miller et al., 1996), Ring Finger Protein 8 (RNF8) and RNF168 (Lilley et al., 2010)), innate immunity (Myeloid differentiation primary response 88 (MyD88) (van Lint et al., 2010)), autophagy (sequestosome 1 and optineurin (Waisner and Kalamvoki, 2019)) and apoptosis (p53 (Boutell and Everett, 2003)). In addition, it has been shown that the E3 activity of ICPO leads to an overall depletion of SUMOylated proteins (Muller and Dejean, 1999; Boutell et al., 2011).

It has been suggested that ICPO also interacts with RE1-Silencing Transcription factor (REST) corepressor (CoREST) (Gu and Roizman, 2007, 2009). Together with histone deacetylases (HDACs) and lysine-specificdemethylase-1 (LSD1), CoREST/REST forms a regulatory complex that represses genes by chromatin condensation (Chong et al., 1995; You et al., 2001; Lakowski et al., 2006). The effect of CoREST/REST on HSV-1 infection could be cell-specific because in some cell types, depletion of CoREST showed no improvement in the replication of ICP0-null mutant viruses compared to the wild-type strain (Everett, 2010).

ICPO activities are thought to keep viral genomes open and uncondensed at early time points post nuclear entry. Interestingly, while ICPO homologues in other alphaherpesviruses are all capable of dismantling PML-NBs and can at least partially complement ICPO activity (Everett et al., 2010), not all are expressed with IE kinetics. This could suggest that either the levels of ICPO homologous are more abundant in the tegument compared to HSV-1 ICPO or 
that some alphaherpesviruses do not require ICPO activity in very early times post nuclear entry. ICPO continues to regulate host responses at later times of infection and during latency and reactivation (Lee et al., 2016; Raja et al., 2016). These results indicate that there are probably more direct and indirect functions of this multitasking protein.

\section{Infected Cell Protein 4 (ICP4)}

The 1298 amino-acid IE protein ICP4 is encoded by the two copies of the RS1 gene found in the short repeat region of the HSV genome (Wadsworth et al., 1975). As many DNA viruses, HSV genome is transcribed by RNA polymerase II (RNA pol II). Via its DNA binding domain (Figure 3C), ICP4 binds the vDNA as a homodimer and functions as either a transcription activator or a repressor of the RNA pol II system (Metzler and Wilcox, 1985; Tunnicliffe et al., 2017). ICP4 can activate most viral promoters, and its presence and proper activation of $E$ and $L$ genes is essential for productive infection. ICP4 was shown to associate with specific DNA sequences found both in the host and viral genomes (Faber and Wilcox, 1986). Recently, it was shown that ICP4 preferentially binds to the viral genomes compared to the host genomes resulting in induction of viral transcription and reduction in host transcripts (Dremel and DeLuca, 2019b).

Activation of genes by ICP4 requires recruitment of TFIID (Transcription factor II D) and the Mediator complex. TFIID is a general TF of the RNA Pol II preinitiation complex. ICP4 interacts with TFIID through its TAF1 subunit (Carrozza and DeLuca, 1996). The Mediator complex subunit involved in the interaction with ICP4 is yet to be determined, but several candidates have been proposed (Lester and DeLuca, 2011).

Repression by ICP4 is less common and limited to specific viral genes (including ICP4 itself) (Faber and Wilcox, 1988; Lium et al., 1996; Liu et al., 2010). In comparison to its activation capacity, repression by ICP4 is more rigid and requires a very specific binding of a tripartite complex (comprised of ICP4, 
TFIID and TFIIB) (Smith et al., 1993) to the gene promoter to block other potential activators (such as the Mediator complex and VP16) (Gu et al., 1995).

The major role of ICP4 is to activate expression of early and late viral genes. ICP4 also binds and activates host genes that are beneficial for viral replication, for example miR-101 (Wang et al., 2016). The overall function of ICP4 is to promote conditions for lytic infection. Live imaging revealed distinct ICP4 foci adjacent to PML-NBs and ICPO colocalization sites (Everett et al., 2003), suggesting an early association of ICP4 with viral genomes, later to be developed into replication compartments. Spatiotemporal study of entering HSV showed heterogeneity amongst those genomes. While some started accumulating ICP4 (initially as distinct foci and later accumulated along the majority of the genome), other genomes showed little to no localization of ICP4 (Sekine et al., 2017). Viral genomes accumulating ICP4 start to decondense and initiate transcription, and ICP4 may have a role in maintaining these genomes relaxed and accessible by coating the viral genomes (Dremel and DeLuca, 2019b). Genomes that did not accumulate ICP4 remained condensed. These results suggest that once ICP4 binds to viral genomes, they commit to lytic infection.

\section{Host factors supporting HSV-1 lytic infection}

Since all viruses are obligate intracellular parasites, they require numerous host factors to complete their life cycle. Many of these host factors are required for viral replication and assembly. Unexpectedly, specific proteins that are part of the host defense response mentioned above are beneficial for the viral replication process. Several virus/host interactions occur early after nuclear entry and influence the outcome of infection.

Most incoming viral genomes remain located near their entry sites, at the nuclear periphery, where they interact with the nuclear lamina (Silva et al., 2008; Silva et al., 2012). Fibroblasts derived from either lamA-/- or lamB1-/knockout mice have reduced viral progeny compared to wild-type murine fibroblasts suggesting that interactions with lamin proteins enhance expression 
and replication from the viral genomes (Mou et al., 2008; Silva et al., 2008). It has been suggested that interactions with the nuclear lamina facilitate assembly of VP16 complexes on the viral genomes (Silva et al., 2012). Despite proximity of the lamina layer to viral genome entry sites, in the analysis by Dembowski et al., lamins associated with the vDNA only at $2 \mathrm{hpi}$, indicating that these lamins are not the first host proteins to interact with viral genomes (Dembowski and DeLuca, 2018). Viral infections that take place a short time before the cell reaches mitosis are less likely to result in a successful infection (Drayman et al., 2017), indicating the importance of intact nucleus for the initiation of the infection.

\section{The single-genome hypothesis}

HSV-1 infection of a given cell is currently thought to result in lytic, latent, or abortive infection. But the observations that permissive and susceptible cells can maintain quiescent viral genomes during lytic infection (Hu et al., 2019) or during abortive/latency like infection (Cohen et al., 2020) suggest that there may be a dynamic continuum of possible outcomes rather than a three-solution decision model. This dynamic continuum could be explained by the singlegenome hypothesis which suggests that each individual incoming viral genome may separately and stochastically result in a different outcome of infection, as has been suggested for bacteriophage lambda (Golding, 2016).

Support for the single-genome hypothesis is provided by the recent results visualizing single incoming genomes that remain condensed in the nucleus while other viral genomes are being replicated (Sekine et al., 2017; Dembowski and DeLuca, 2018). Small undeveloped RCs were detected within larger RCs using dual-color fluorescent in-situ hybridization (Tomer et al., 2019). Even in latently infected neurons, several patterns of quiescent viral genomes have been observed, and in some cells combination of these patterns are detected (Maroui et al., 2016). The identification of condensed inaccessible viral genomes throughout the lytic infection further support this model (Hu et al., 2019). 
The concept that not all incoming genomes will share the same fate suggests that productive lytic infection can initiate from only one or few incoming genomes whereas other genomes in the same cell do not contribute to the lytic process or to the genetic pool of progeny viruses (Figure 4). Indeed, each entering genome can form its own RC (Sourvinos and Everett, 2002; Kobiler et al., 2011; Tomer et al., 2019) raising the possibility that there is partial autonomous activity of each incoming genome. Furthermore, only a limited number of incoming alphaherpesviral genomes can initiate expression and replication per cell (Phelan et al., 1997; Kobiler et al., 2010; Kobiler et al., 2011; Taylor et al., 2012; Cohen and Kobiler, 2016; Shapira et al., 2016; Sekine et al., 2017). Since this limited number does not correlate linearly with MOI (i.e., raising the $\mathrm{MOI}$ from 10 to 100 results in the increase of the average number of genomes from $\sim 4$ to $\sim 7$ ), not all incoming genomes likely initiate expression and replication.

Current paradigm is that host factors try to suppress the incoming viral genomes whereas viral proteins (VP16, ICP0 and ICP4) are required to overcome this suppression and initiate lytic infection. However, this is an

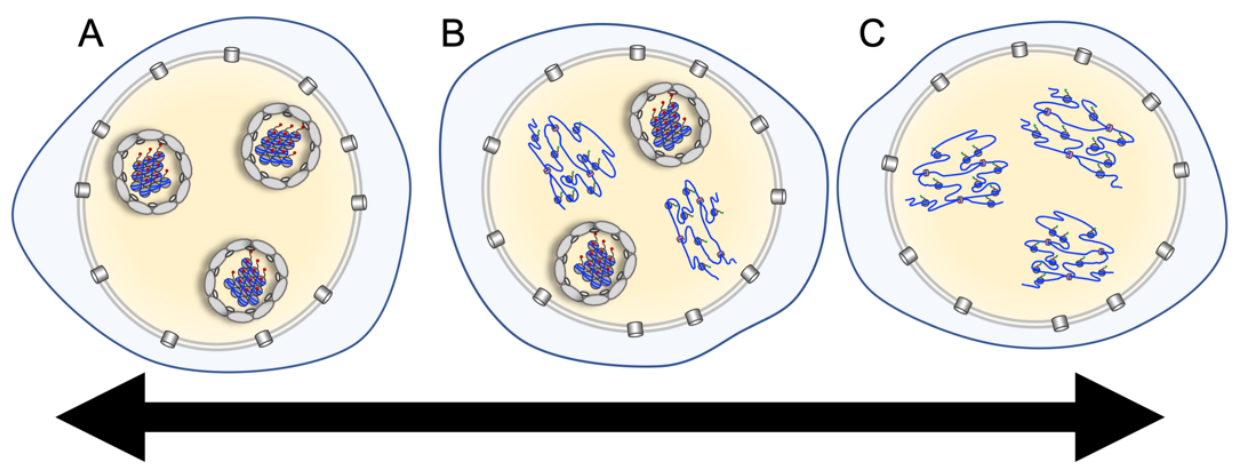

Figure 4. The single-genome hypothesis. A schematic illustration of dynamic continuum of outcomes of infection according to the single genome concept. (A) represent a cell that will follow the abortive or latent cycle as all viral genomes are repressed. (B-C) represent cells that will follow the lytic infection as not all entering genomes will be silenced. 
oversimplified view of a complex molecular system that has evolved to allow both the lytic infection as well as the latent infection. This intricate system provides the virus with the opportunity to select either outcome and allows for specific genetic, structural or environmental clues to influence the decision between different outcomes. The single-genome hypothesis suggests that local interactions between viral genomes and viral or host proteins are key for determining the fate of each incoming genome. The probability of any viral genome to encounter either components of the host antiviral defenses or the VP16 complex would then determine the specific outcome for a particular genome. Thus, a rise in the level of antiviral proteins would be expected to increase the likelihood that they would bind the entering genomes and vice versa. Similarly, when VP16 needs to diffuse for a long distance from the viral cellular entry point towards the nucleus, which happens during infection of peripheral neurons where axon ending can be at least few centimeters away from cell body (even for trigeminal neurons in young kids), the likelihood of viral genomes moving inside the capsid on microtubules towards the nucleus to interact with the freely diffusing VP16 is low, increasing the chance for latency (Knipe and Cliffe, 2008). High levels of VP16 complexes (as expected at high $\mathrm{MOI}$ ) would then be expected to increase the likelihood for lytic infection. Indeed, ICP0-null viruses can complete infection in most cell lines only at high MOI (Stow and Stow, 1986; Sacks and Schaffer, 1987), suggesting that the high probability to interact with VP16 complexes can overcome host defense silencing mechanisms.

\section{Conclusions}

Here, we have summarized current knowledge on the decision processes of incoming HSV-1 genomes. We highlighted three major intrinsic host mechanisms that inhibit incoming genomes, and three viral proteins that counteract these mechanisms. We suggested that instead of looking on the outcome of the entire cell to study the viral decision, one should focus on individual viral genomes. 
Three major intrinsic nuclear mechanisms are thought to promote HSV-1 genomes silencing: PML-NBs, DDR and histone modifications. As described above, each of these nuclear mechanisms is a multi-protein response, and furthermore, there is crosstalk between them. Therefore, elucidating the roles of specific proteins is challenging. Other challenges result from the finding that inhibition of specific posttranslational modification of histones during viral infection may cause greater effects on the host genome than on viral genomes, adding to the complexity of experimental analysis (Shapira et al., 2016; Arbuckle et al., 2017; Kulej et al., 2017).

Some specific proteins from each host defense response, including PML-NBs, DDR, and histone modifications, can be beneficial for viral replication process (Mohni et al., 2011; Mohni et al., 2013; Kristie, 2015; Xu et al., 2016; Edwards et al., 2018). This might be part of a viral strategy to dismantle host defense mechanisms by reusing parts of these system for its own replication. Alternatively, since these proteins are recruited by the host to inhibit viral replication and they became closely associated with the viral genomes, the virus may have evolved to utilize these nearby specific proteins.

Levels of the viral proteins VP16, ICP0 and ICP4 are critical to promoting lytic infection. VP16 levels are determined by the amount of VP16 arriving within the tegument (differences can be due to MOI and levels of VP16 within the viral particle) and diffusion from the entry site to the nucleus, allowing finetuning of outcome of the infection process to these conditions. While ICPO and ICP4 are also in the tegument (Yao and Courtney, 1989, 1992; Loret et al., 2008) the functional role of these proteins within viral particles is not fully understood (Delboy and Nicola, 2011; Pritchard et al., 2013). But, unlike VP16, which is transcribed from a late gene, ICPO and ICP4 are transcribed from IE genes and would become available very early in infection. The genes encoding ICPO and ICP4 are among very few genes that are found in two copies. Two copies for a single gene is a rare phenomenon in virology even among large DNA viruses. One possible explanation for this phenomenon can be the importance of these genes for the infection process requiring that at least one 
copy should be intact. Alternatively, duplicate copies would allow for a more rapid synthesis of mRNA to meet the need for rapid accumulation of a viral protein.

\section{Future trends}

Elucidation of the rapid events that occur following entry of the viral genomes into the nucleus remains a major challenge for the ongoing research. One of the key problems is the lack of synchrony in the entry process. Better synchronization is required to dissect very early events. Currently, one of the best way to synchronize nuclear entry is using the tsB7 mutant (or its derivatives), which permits the capsids to bind the nuclear pore complex at high temperature but allows rapid injection of viral genome into the nucleus only at low temperature (Batterson et al., 1983; Abaitua et al., 2009; Abaitua et al., 2011; Ralph et al., 2017). However, these temperature changes might affect other viral or host processes (Ralph et al., 2017). Alternative approaches for synchronizing nuclear entry are needed.

Even if synchronous nuclear entry could be achieved, according to the singlegenome hypothesis, it is likely that each genome has a different fate. Can different early events be detected at a single-genome resolution? Can these early events determine the outcomes for specific genomes?

Finally, the single-genome hypothesis suggests that even a single genome is sufficient to initiate a lytic infection. The virus might have evolved a mechanism to devote most of its efforts to a single or very few genomes, i.e., the viral proteins (VP16 and the immediate early genes) interact with only a few of the incoming viral genomes while the cells suppress the rest of the incoming genomes. Can such a mechanism exist? Can this be the reason for the limited number of genomes expressed in individual cells?

Many questions regarding the early nuclear events remain unanswered. Here, we have discussed only a few of those. While some of these questions are currently too challenging to address due to technological limitations, with rapid 
improvements in technology, it is only a matter of time until these and other questions are deciphered.

\section{References}

Abaitua, F., Daikoku, T., Crump, C.M., Bolstad, M., and O'Hare, P. (2011). A single mutation responsible for temperature-sensitive entry and assembly defects in the VP1-2 protein of herpes simplex virus. J Virol 85, 2024-2036. https://dx.doi.org/10.1128/JVI.01895-10

Abaitua, F., Souto, R.N., Browne, H., Daikoku, T., and O'Hare, P. (2009). Characterization of the herpes simplex virus (HSV)-1 tegument protein VP1-2 during infection with the HSV temperature-sensitive mutant tsB7. J Gen Virol 90, 2353-2363. https://dx.doi.org/10.1099/vir.0.012492-0

Alandijany, T. (2019). Host Intrinsic and Innate Intracellular Immunity During Herpes Simplex Virus Type 1 (HSV-1) Infection. Front Microbiol 10, 2611. https://dx.doi.org/10.3389/fmicb.2019.02611

Alandijany, T., Roberts, A.P.E., Conn, K.L., Loney, C., McFarlane, S., Orr, A., and Boutell, C. (2018). Distinct temporal roles for the promyelocytic leukaemia $(P M L)$ protein in the sequential regulation of intracellular host immunity to HSV-1 infection. PLoS Pathog 14, e1006769. https://dx.doi.org/ 10.1371/journal.ppat.1006769

Arbuckle, J.H., Gardina, P.J., Gordon, D.N., Hickman, H.D., Yewdell, J.W., Pierson, T.C., Myers, T.G., and Kristie, T.M. (2017). Inhibitors of the Histone Methyltransferases EZH2/1 Induce a Potent Antiviral State and Suppress Infection by Diverse Viral Pathogens. MBio 8. https://dx.doi.org/10.1128/ mBio.01141-17

Aurelian, L., and Roizman, B. (1964). The Host Range of Herpes Simplex Virus; Interferon, Viral DNA, and Antigen Synthesis in Abortive Infection of Dog Kidney Cells. Virology 22, 452-461

Aurelian, L., and Roizman, B. (1965). Abortive Infection of Canine Cells by Herpes Simplex Virus. li. Alternative Suppression of Synthesis of Interferon and Viral Constituents. J Mol Biol 11, 539-548 
Babb, R., Huang, C.C., Aufiero, D.J., and Herr, W. (2001). DNA recognition by the herpes simplex virus transactivator VP16: a novel DNA-binding structure. Mol Cell Biol 21, 4700-4712. https://dx.doi.org/10.1128/MCB.21.14.4700-4712.2001

Batterson, W., Furlong, D., and Roizman, B. (1983). Molecular genetics of herpes simplex virus. VIII. further characterization of a temperature-sensitive mutant defective in release of viral DNA and in other stages of the viral reproductive cycle. J Virol 45, 397-407

Biswas, S., and Rao, C.M. (2018). Epigenetic tools (The Writers, The Readers and The Erasers) and their implications in cancer therapy. Eur J Pharmacol. https://dx.doi.org/10.1016/j.ejphar.2018.08.021

Boutell, C., Cuchet-Lourenco, D., Vanni, E., Orr, A., Glass, M., McFarlane, S., and Everett, R.D. (2011). A viral ubiquitin ligase has substrate preferential SUMO targeted ubiquitin ligase activity that counteracts intrinsic antiviral defence. PLoS Pathog 7, e1002245. https://dx.doi.org/10.1371/journal.ppat. 1002245

Boutell, C., and Everett, R.D. (2003). The herpes simplex virus type 1 (HSV-1) regulatory protein ICPO interacts with and Ubiquitinates p53. J Biol Chem 278, 36596-36602. https://dx.doi.org/10.1074/jbc.M300776200

Boutell, C., and Everett, R.D. (2013). Regulation of alphaherpesvirus infections by the ICP0 family of proteins. J Gen Virol 94, 465-481. https://dx.doi.org/ 10.1099/vir.0.048900-0

Brown, J.C. (2017). Herpes Simplex Virus Latency: The DNA Repair-Centered Pathway. Adv Virol 2017, 7028194. https://dx.doi.org/10.1155/2017/7028194

Canning, M., Boutell, C., Parkinson, J., and Everett, R.D. (2004). A RING finger ubiquitin ligase is protected from autocatalyzed ubiquitination and degradation by binding to ubiquitin-specific protease USP7. J Biol Chem 279, 38160-38168. https://dx.doi.org/10.1074/jbc.M402885200

Carrozza, M.J., and DeLuca, N.A. (1996). Interaction of the viral activator protein ICP4 with TFIID through TAF250. Mol Cell Biol 16, 3085-3093

Catez, F., Picard, C., Held, K., Gross, S., Rousseau, A., Theil, D., Sawtell, N., Labetoulle, M., and Lomonte, P. (2012). HSV-1 genome subnuclear positioning and associations with host-cell PML-NBs and centromeres 
regulate LAT locus transcription during latency in neurons. PLoS Pathog 8 , e1002852. https://dx.doi.org/10.1371/journal.ppat.1002852

Chelbi-Alix, M.K., and de The, H. (1999). Herpes virus induced proteasomedependent degradation of the nuclear bodies-associated PML and Sp100 proteins. Oncogene 18, 935-941. https://dx.doi.org/10.1038/sj.onc.1202366

Chong, J.A., Tapia-Ramirez, J., Kim, S., Toledo-Aral, J.J., Zheng, Y., Boutros, M.C., Altshuller, Y.M., Frohman, M.A., Kraner, S.D., and Mandel, G. (1995). REST: a mammalian silencer protein that restricts sodium channel gene expression to neurons. Cell 80, 949-957

Cliffe, A.R., Garber, D.A., and Knipe, D.M. (2009). Transcription of the herpes simplex virus latency-associated transcript promotes the formation of facultative heterochromatin on lytic promoters. J Virol 83, 8182-8190. https:// dx.doi.org/10.1128/JVI.00712-09

Cohen, C., Corpet, A., Roubille, S., Maroui, M.A., Poccardi, N., Rousseau, A., Kleijwegt, C., Binda, O., Texier, P., Sawtell, N., et al. (2018). Promyelocytic leukemia (PML) nuclear bodies (NBs) induce latent/quiescent HSV-1 genomes chromatinization through a PML NB/Histone H3.3/H3.3 Chaperone Axis. PLoS Pathog 14, e1007313. https://dx.doi.org/10.1371/journal.ppat. 1007313

Cohen, E.M., Avital, N., Shamay, M., and Kobiler, O. (2020). Abortive herpes simplex virus infection of nonneuronal cells results in quiescent viral genomes that can reactivate. Proc Natl Acad Sci U S A 117, 635-640. https:// dx.doi.org/10.1073/pnas.1910537117

Cohen, E.M., and Kobiler, O. (2016). Gene Expression Correlates with the Number of Herpes Viral Genomes Initiating Infection in Single Cells. PLoS Pathog 12, e1006082. https://dx.doi.org/10.1371/journal.ppat.1006082

Cuchet, D., Sykes, A., Nicolas, A., Orr, A., Murray, J., Sirma, H., Heeren, J., Bartelt, A., and Everett, R.D. (2011). PML isoforms I and II participate in PMLdependent restriction of HSV-1 replication. J Cell Sci 124, 280-291. https:// dx.doi.org/10.1242/jcs.075390

Cuchet-Lourenco, D., Boutell, C., Lukashchuk, V., Grant, K., Sykes, A., Murray, J., Orr, A., and Everett, R.D. (2011). SUMO pathway dependent recruitment 
of cellular repressors to herpes simplex virus type 1 genomes. PLoS Pathog 7, e1002123. https://dx.doi.org/10.1371/journal.ppat.1002123

de Bruyn Kops, A., and Knipe, D.M. (1988). Formation of DNA replication structures in herpes virus-infected cells requires a viral DNA binding protein. Cell 55, 857-868

Delboy, M.G., and Nicola, A.V. (2011). A pre-immediate-early role for tegument ICPO in the proteasome-dependent entry of herpes simplex virus. J Virol 85, 5910-5918. https://dx.doi.org/10.1128/JVI.00267-11

Dembowski, J.A., and DeLuca, N.A. (2015). Selective recruitment of nuclear factors to productively replicating herpes simplex virus genomes. PLoS Pathog 11, e1004939. https://dx.doi.org/10.1371/journal.ppat.1004939

Dembowski, J.A., and DeLuca, N.A. (2018). Temporal Viral Genome-Protein Interactions Define Distinct Stages of Productive Herpesviral Infection. MBio 9. https://dx.doi.org/10.1128/mBio.01182-18

Dembowski, J.A., Dremel, S.E., and DeLuca, N.A. (2017). Replication-Coupled Recruitment of Viral and Cellular Factors to Herpes Simplex Virus Type 1 Replication Forks for the Maintenance and Expression of Viral Genomes. PLoS Pathog 13, e1006166. https://dx.doi.org/10.1371/journal.ppat.1006166

Deshmane, S.L., and Fraser, N.W. (1989). During latency, herpes simplex virus type 1 DNA is associated with nucleosomes in a chromatin structure. $\mathrm{J}$ Virol $63,943-947$

Diner, B.A., Lum, K.K., Toettcher, J.E., and Cristea, I.M. (2016). Viral DNA Sensors IFI16 and Cyclic GMP-AMP Synthase Possess Distinct Functions in Regulating Viral Gene Expression, Immune Defenses, and Apoptotic Responses during Herpesvirus Infection. MBio 7. https://dx.doi.org/10.1128/ mBio.01553-16

Drayman, N., Karin, O., Mayo, A., Danon, T., Shapira, L., Rafael, D., Zimmer, A., Bren, A., Kobiler, O., and Alon, U. (2017). Dynamic Proteomics of Herpes Simplex Virus Infection. MBio 8. https://dx.doi.org/10.1128/mBio.01612-17

Drayman, N., Patel, P., Vistain, L., and Tay, S. (2019). HSV-1 single-cell analysis reveals the activation of anti-viral and developmental programs in distinct sub-populations. Elife 8. https://dx.doi.org/10.7554/eLife.46339 
Dremel, S.E., and DeLuca, N.A. (2019a). Genome replication affects transcription factor binding mediating the cascade of herpes simplex virus transcription. Proc Natl Acad Sci U S A 116, 3734-3739. https://dx.doi.org/ 10.1073/pnas.1818463116

Dremel, S.E., and DeLuca, N.A. (2019b). Herpes simplex viral nucleoprotein creates a competitive transcriptional environment facilitating robust viral transcription and host shut off. Elife 8. https://dx.doi.org/10.7554/eLife.51109

Edwards, T.G., and Bloom, D.C. (2019). Lund Human Mesencephalic (LUHMES) Neuronal Cell Line Supports Herpes Simplex Virus 1 Latency In Vitro. J Virol 93. https://dx.doi.org/10.1128/JVI.02210-18

Edwards, T.G., Bloom, D.C., and Fisher, C. (2018). The ATM and Rad3Related (ATR) Protein Kinase Pathway Is Activated by Herpes Simplex Virus 1 and Required for Efficient Viral Replication. J Virol 92. https://dx.doi.org/ 10.1128/JVI.01884-17

El Bilali, N., Duron, J., Gingras, D., and Lippe, R. (2017). Quantitative Evaluation of Protein Heterogeneity within Herpes Simplex Virus 1 Particles. J Virol 91. https://dx.doi.org/10.1128/JVI.00320-17

Everett, R.D. (1988). Analysis of the functional domains of herpes simplex virus type 1 immediate-early polypeptide Vmw110. J Mol Biol 202, 87-96

Everett, R.D. (2010). Depletion of CoREST does not improve the replication of ICP0 null mutant herpes simplex virus type 1. J Virol 84, 3695-3698. https:// dx.doi.org/10.1128/JVI.00021-10

Everett, R.D. (2013). The spatial organization of DNA virus genomes in the nucleus. PLoS Pathog 9, e1003386. https://dx.doi.org/10.1371/journal.ppat. 1003386

Everett, R.D., Barlow, P., Milner, A., Luisi, B., Orr, A., Hope, G., and Lyon, D. (1993). A novel arrangement of zinc-binding residues and secondary structure in the $\mathrm{C} 3 \mathrm{HC} 4$ motif of an alpha herpes virus protein family. $\mathrm{J} \mathrm{Mol}$ Biol 234, 1038-1047. https://dx.doi.org/10.1006/jmbi.1993.1657

Everett, R.D., Boutell, C., McNair, C., Grant, L., and Orr, A. (2010). Comparison of the biological and biochemical activities of several members of the alphaherpesvirus ICP0 family of proteins. J Virol 84, 3476-3487. https:// dx.doi.org/10.1128/JVI.02544-09 
Everett, R.D., and Murray, J. (2005). ND10 components relocate to sites associated with herpes simplex virus type 1 nucleoprotein complexes during virus infection. J Virol 79, 5078-5089. https://dx.doi.org/10.1128/JVI. 79.8.5078-5089.2005

Everett, R.D., Parada, C., Gripon, P., Sirma, H., and Orr, A. (2008). Replication of ICP0-null mutant herpes simplex virus type 1 is restricted by both PML and Sp100. J Virol 82, 2661-2672. https://dx.doi.org/10.1128/JVI.02308-07

Everett, R.D., Sourvinos, G., and Orr, A. (2003). Recruitment of herpes simplex virus type 1 transcriptional regulatory protein ICP4 into foci juxtaposed to ND10 in live, infected cells. J Virol 77, 3680-3689

Faber, S.W., and Wilcox, K.W. (1986). Association of the herpes simplex virus regulatory protein ICP4 with specific nucleotide sequences in DNA. Nucleic Acids Res 14, 6067-6083. https://dx.doi.org/10.1093/nar/14.15.6067

Faber, S.W., and Wilcox, K.W. (1988). Association of herpes simplex virus regulatory protein ICP4 with sequences spanning the ICP4 gene transcription initiation site. Nucleic Acids Res 16, 555-570

Frenkel, N., and Roizman, B. (1972). Separation of the herpesvirus deoxyribonucleic acid duplex into unique fragments and intact strand on sedimentation in alkaline gradients. J Virol 10, 565-572

Gibeault, R.L., Conn, K.L., Bildersheim, M.D., and Schang, L.M. (2016). An Essential Viral Transcription Activator Modulates Chromatin Dynamics. PLoS Pathog 12, e1005842. https://dx.doi.org/10.1371/journal.ppat.1005842

Glass, M., and Everett, R.D. (2013). Components of promyelocytic leukemia nuclear bodies (ND10) act cooperatively to repress herpesvirus infection. J Virol 87, 2174-2185. https://dx.doi.org/10.1128/JVI.02950-12

Golding, I. (2016). Single-Cell Studies of Phage lambda: Hidden Treasures Under Occam's Rug. Annu Rev Virol 3, 453-472. https://dx.doi.org/10.1146/ annurev-virology-110615-042127

Gu, B., Kuddus, R., and DeLuca, N.A. (1995). Repression of activatormediated transcription by herpes simplex virus ICP4 via a mechanism involving interactions with the basal transcription factors TATA-binding protein and TFIIB. Mol Cell Biol 15, 3618-3626 
Gu, H., and Roizman, B. (2007). Herpes simplex virus-infected cell protein 0 blocks the silencing of viral DNA by dissociating histone deacetylases from the CoREST-REST complex. Proc Natl Acad Sci U S A 104, 17134-17139. https://dx.doi.org/10.1073/pnas.0707266104

$\mathrm{Gu}, \mathrm{H}$., and Roizman, B. (2009). The two functions of herpes simplex virus 1 ICP0, inhibition of silencing by the CoREST/REST/HDAC complex and degradation of PML, are executed in tandem. J Virol 83, 181-187. https:// dx.doi.org/10.1128/JVI.01940-08

$\mathrm{Gu}, \mathrm{H}$., and Zheng, Y. (2016). Role of ND10 nuclear bodies in the chromatin repression of HSV-1. Virol J 13, 62. https://dx.doi.org/10.1186/ s12985-016-0516-4

Hancock, M.H., Cliffe, A.R., Knipe, D.M., and Smiley, J.R. (2010). Herpes simplex virus VP16, but not ICP0, is required to reduce histone occupancy and enhance histone acetylation on viral genomes in U2OS osteosarcoma cells. J Virol 84, 1366-1375. https://dx.doi.org/10.1128/JVI.01727-09

Harris, R.A., and Preston, C.M. (1991). Establishment of latency in vitro by the herpes simplex virus type 1 mutant in1814. J Gen Virol 72 ( Pt 4), 907-913. https://dx.doi.org/10.1099/0022-1317-72-4-907

Herr, W., and Cleary, M.A. (1995). The POU domain: versatility in transcriptional regulation by a flexible two-in-one DNA-binding domain. Genes Dev 9, 1679-1693

Herrera, F.J., and Triezenberg, S.J. (2004). VP16-dependent association of chromatin-modifying coactivators and underrepresentation of histones at immediate-early gene promoters during herpes simplex virus infection. J Virol 78, 9689-9696. https://dx.doi.org/10.1128/JVI.78.18.9689-9696.2004

Hirai, H., Tani, T., and Kikyo, N. (2010). Structure and functions of powerful transactivators: VP16, MyoD and FoxA. Int J Dev Biol 54, 1589-1596. https:// dx.doi.org/10.1387/ijdb.103194hh

Honess, R.W., and Roizman, B. (1974). Regulation of herpesvirus macromolecular synthesis. I. Cascade regulation of the synthesis of three groups of viral proteins. J Virol 14, 8-19

Honess, R.W., and Roizman, B. (1975). Regulation of herpesvirus macromolecular synthesis: sequential transition of polypeptide synthesis 
requires functional viral polypeptides. Proc Natl Acad Sci U S A 72, 1276-1280

Hu, H.L., Srinivas, K.P., Mohr, I., Huang, T.T., and Wilson, A.C. (2020). Using Primary SCG Neuron Cultures to Study Molecular Determinants of HSV-1 Latency and Reactivation. Methods Mol Biol 2060, 263-277. https:// dx.doi.org/10.1007/978-1-4939-9814-2_14

Hu, M., Depledge, D.P., Flores Cortes, E., Breuer, J., and Schang, L.M. (2019). Chromatin dynamics and the transcriptional competence of HSV-1 genomes during lytic infections. PLoS Pathog 15, e1008076. https://dx.doi.org/10.1371/ journal.ppat.1008076

Huang, J., Kent, J.R., Placek, B., Whelan, K.A., Hollow, C.M., Zeng, P.Y., Fraser, N.W., and Berger, S.L. (2006). Trimethylation of histone H3 lysine 4 by Set 1 in the lytic infection of human herpes simplex virus 1. J Virol 80 , 5740-5746. https://dx.doi.org/10.1128/JVI.00169-06

Karttunen, H., Savas, J.N., McKinney, C., Chen, Y.H., Yates, J.R., 3rd, Hukkanen, V., Huang, T.T., and Mohr, I. (2014). Co-opting the Fanconi anemia genomic stability pathway enables herpesvirus DNA synthesis and productive growth. Mol Cell 55, 111-122. https://dx.doi.org/10.1016/j.molcel. 2014.05.020

Kelly, B.J., Fraefel, C., Cunningham, A.L., and Diefenbach, R.J. (2009). Functional roles of the tegument proteins of herpes simplex virus type 1. Virus Res 145, 173-186. https://dx.doi.org/10.1016/j.virusres.2009.07.007

Kent, J.R., Zeng, P.Y., Atanasiu, D., Gardner, J., Fraser, N.W., and Berger, S.L. (2004). During lytic infection herpes simplex virus type 1 is associated with histones bearing modifications that correlate with active transcription. J Virol 78, 10178-10186. https://dx.doi.org/10.1128/JVI.78.18.10178-10186.2004

Kieff, E.D., Bachenheimer, S.L., and Roizman, B. (1971). Size, composition, and structure of the deoxyribonucleic acid of herpes simplex virus subtypes 1 and 2. J Virol 8, 125-132

Knipe, D.M., and Cliffe, A. (2008). Chromatin control of herpes simplex virus lytic and latent infection. Nat Rev Microbiol 6, 211-221. https://dx.doi.org/ 10.1038/nrmicro1794 
Kobiler, O., Brodersen, P., Taylor, M.P., Ludmir, E.B., and Enquist, L.W. (2011). Herpesvirus replication compartments originate with single incoming viral genomes. MBio 2. https://dx.doi.org/10.1128/mBio.00278-11

Kobiler, O., Lipman, Y., Therkelsen, K., Daubechies, I., and Enquist, L.W. (2010). Herpesviruses carrying a Brainbow cassette reveal replication and expression of limited numbers of incoming genomes. Nat Commun 1, 146. https://dx.doi.org/10.1038/ncomms 1145

Kobiler, O., and Weitzman, M.D. (2019). Herpes simplex virus replication compartments: From naked release to recombining together. PLoS Pathog 15, e1007714. https://dx.doi.org/10.1371/journal.ppat.1007714

Komatsu, T., Nagata, K., and Wodrich, H. (2016). The Role of Nuclear Antiviral Factors against Invading DNA Viruses: The Immediate Fate of Incoming Viral Genomes. Viruses 8. https://dx.doi.org/10.3390/v8100290

Koyuncu, O.O., MacGibeny, M.A., and Enquist, L.W. (2018). Latent versus productive infection: the alpha herpesvirus switch. Future Virol 13, 431-443. https://dx.doi.org/10.2217/fvl-2018-0023

Kristie, T.M. (2015). Dynamic modulation of HSV chromatin drives initiation of infection and provides targets for epigenetic therapies. Virology 479-480, 555-561. https://dx.doi.org/10.1016/j.virol.2015.01.026

Kristie, T.M., LeBowitz, J.H., and Sharp, P.A. (1989). The octamer-binding proteins form multi-protein--DNA complexes with the HSV alpha TIF regulatory protein. EMBO J 8, 4229-4238

Kubat, N.J., Tran, R.K., McAnany, P., and Bloom, D.C. (2004). Specific histone tail modification and not DNA methylation is a determinant of herpes simplex virus type 1 latent gene expression. J Virol 78, 1139-1149

Kulej, K., Avgousti, D.C., Sidoli, S., Herrmann, C., Della Fera, A.N., Kim, E.T., Garcia, B.A., and Weitzman, M.D. (2017). Time-resolved Global and Chromatin Proteomics during Herpes Simplex Virus Type 1 (HSV-1) Infection. Mol Cell Proteomics 16, S92-S107. https://dx.doi.org/10.1074/ mcp.M116.065987

Kwiatkowski, D.L., Thompson, H.W., and Bloom, D.C. (2009). The polycomb group protein Bmi1 binds to the herpes simplex virus 1 latent genome and 
maintains repressive histone marks during latency. J Virol 83, 8173-8181. https://dx.doi.org/10.1128/JVI.00686-09

Kwong, A.D., and Frenkel, N. (1987). Herpes simplex virus-infected cells contain a function(s) that destabilizes both host and viral mRNAs. Proc Natl Acad Sci U S A 84, 1926-1930

Kwong, A.D., Kruper, J.A., and Frenkel, N. (1988). Herpes simplex virus virion host shutoff function. J Virol 62, 912-921

La Boissiere, S., Hughes, T., and O'Hare, P. (1999). HCF-dependent nuclear import of VP16. EMBO J 18, 480-489. https://dx.doi.org/10.1093/emboj/ 18.2.480

Lacasse, J.J., and Schang, L.M. (2010). During lytic infections, herpes simplex virus type 1 DNA is in complexes with the properties of unstable nucleosomes. J Virol 84, 1920-1933. https://dx.doi.org/10.1128/JVI.01934-09

Lacasse, J.J., and Schang, L.M. (2012). Herpes Simplex Virus 1 DNA Is in Unstable Nucleosomes throughout the Lytic Infection Cycle, and the Instability of the Nucleosomes Is Independent of DNA Replication. Journal of Virology 86, 11287-11300. https://dx.doi.org/10.1128/Jvi.01468-12

Lakowski, B., Roelens, I., and Jacob, S. (2006). CoREST-like complexes regulate chromatin modification and neuronal gene expression. J Mol Neurosci 29, 227-239. https://dx.doi.org/10.1385/JMN:29:3:227

Lallemand-Breitenbach, V., and de The, H. (2018). PML nuclear bodies: from architecture to function. Curr Opin Cell Biol 52, 154-161. https://dx.doi.org/ 10.1016/j.ceb.2018.03.011

Lanctot, C., Cheutin, T., Cremer, M., Cavalli, G., and Cremer, T. (2007). Dynamic genome architecture in the nuclear space: regulation of gene expression in three dimensions. Nat Rev Genet 8, 104-115. https://dx.doi.org/ 10.1038/nrg2041

Leary, K., Connor, J.R., and Morahan, P.S. (1985). Comparison of herpes simplex virus type 1 DNA replication and virus production in murine bone marrow-derived and resident peritoneal macrophages. J Gen Virol 66 ( Pt 5), 1123-1129. https://dx.doi.org/10.1099/0022-1317-66-5-1123

Lee, J.S., Raja, P., and Knipe, D.M. (2016). Herpesviral ICP0 Protein Promotes Two Waves of Heterochromatin Removal on an Early Viral Promoter during 
Lytic Infection. MBio 7, e02007-02015. https://dx.doi.org/10.1128/mBio. 02007-15

Lees-Miller, S.P., Long, M.C., Kilvert, M.A., Lam, V., Rice, S.A., and Spencer, C.A. (1996). Attenuation of DNA-dependent protein kinase activity and its catalytic subunit by the herpes simplex virus type 1 transactivator ICPO. J Virol 70, 7471-7477

Lester, J.T., and DeLuca, N.A. (2011). Herpes simplex virus 1 ICP4 forms complexes with TFIID and mediator in virus-infected cells. J Virol 85, 5733-5744. https://dx.doi.org/10.1128/JVI.00385-11

Liang, Y., Vogel, J.L., Narayanan, A., Peng, H., and Kristie, T.M. (2009). Inhibition of the histone demethylase LSD1 blocks alpha-herpesvirus lytic replication and reactivation from latency. Nat Med 15, 1312-1317. https:// dx.doi.org/10.1038/nm.2051

Lilley, C.E., Carson, C.T., Muotri, A.R., Gage, F.H., and Weitzman, M.D. (2005). DNA repair proteins affect the lifecycle of herpes simplex virus 1. Proc Natl Acad Sci U S A 102, 5844-5849. https://dx.doi.org/10.1073/pnas.0501916102 Lilley, C.E., Chaurushiya, M.S., Boutell, C., Everett, R.D., and Weitzman, M.D. (2011). The intrinsic antiviral defense to incoming HSV-1 genomes includes specific DNA repair proteins and is counteracted by the viral protein ICPO. PLoS Pathog 7, e1002084. https://dx.doi.org/10.1371/journal.ppat.1002084

Lilley, C.E., Chaurushiya, M.S., Boutell, C., Landry, S., Suh, J., Panier, S., Everett, R.D., Stewart, G.S., Durocher, D., and Weitzman, M.D. (2010). A viral E3 ligase targets RNF8 and RNF168 to control histone ubiquitination and DNA damage responses. EMBO J 29, 943-955. https://dx.doi.org/ 10.1038/emboj.2009.400

Linnavuori, K., and Hovi, T. (1983). Restricted replication of herpes simplex virus in human monocyte cultures: role of interferon. Virology 130, 1-9

Liu, M., Rakowski, B., Gershburg, E., Weisend, C.M., Lucas, O., Schmidt, E.E., and Halford, W.P. (2010). ICPO antagonizes ICP4-dependent silencing of the herpes simplex virus ICPO gene. PLoS One 5, e8837. https://dx.doi.org/ 10.1371/journal.pone.0008837 
Lium, E.K., Panagiotidis, C.A., Wen, X., and Silverstein, S. (1996). Repression of the alpha0 gene by ICP4 during a productive herpes simplex virus infection. J Virol 70, 3488-3496

Lium, E.K., Panagiotidis, C.A., Wen, X., and Silverstein, S.J. (1998). The NH2 terminus of the herpes simplex virus type 1 regulatory protein ICP0 contains a promoter-specific transcription activation domain. J Virol 72, 7785-7795

Lium, E.K., and Silverstein, S. (1997). Mutational analysis of the herpes simplex virus type $1 \mathrm{ICPO} \mathrm{C} 3 \mathrm{HC} 4$ zinc ring finger reveals a requirement for ICPO in the expression of the essential alpha27 gene. J Virol 71, 8602-8614

Loret, S., Guay, G., and Lippe, R. (2008). Comprehensive characterization of extracellular herpes simplex virus type 1 virions. J Virol 82, 8605-8618. https://dx.doi.org/10.1128/JVI.00904-08

Lukashchuk, V., and Everett, R.D. (2010). Regulation of ICP0-null mutant herpes simplex virus type 1 infection by ND10 components ATRX and hDaxx. J Virol 84, 4026-4040. https://dx.doi.org/10.1128/JVI.02597-09

Ma, J.Z., Russell, T.A., Spelman, T., Carbone, F.R., and Tscharke, D.C. (2014). Lytic gene expression is frequent in HSV-1 latent infection and correlates with the engagement of a cell-intrinsic transcriptional response. PLoS Pathog 10 , e1004237. https://dx.doi.org/10.1371/journal.ppat.1004237

Maroui, M.A., Calle, A., Cohen, C., Streichenberger, N., Texier, P., Takissian, J., Rousseau, A., Poccardi, N., Welsch, J., Corpet, A., et al. (2016). Latency Entry of Herpes Simplex Virus 1 Is Determined by the Interaction of Its Genome with the Nuclear Environment. PLoS Pathog 12, e1005834. https:// dx.doi.org/10.1371/journal.ppat.1005834

Marshall, K.R., Lachmann, R.H., Efstathiou, S., Rinaldi, A., and Preston, C.M. (2000). Long-term transgene expression in mice infected with a herpes simplex virus type 1 mutant severely impaired for immediate-early gene expression. J Virol 74, 956-964

Maul, G.G., Ishov, A.M., and Everett, R.D. (1996). Nuclear domain 10 as preexisting potential replication start sites of herpes simplex virus type-1. Virology 217, 67-75. https://dx.doi.org/10.1006/viro.1996.0094

McFarlane, S., Orr, A., Roberts, A.P.E., Conn, K.L., Iliev, V., Loney, C., da Silva Filipe, A., Smollett, K., Gu, Q., Robertson, N., et al. (2019). The histone 
chaperone HIRA promotes the induction of host innate immune defences in response to HSV-1 infection. PLoS Pathog 15, e1007667. https://dx.doi.org/ 10.1371/journal.ppat.1007667

McGeoch, D.J., Rixon, F.J., and Davison, A.J. (2006). Topics in herpesvirus genomics and evolution. Virus Res 117, 90-104. https://dx.doi.org/10.1016/ j.virusres.2006.01.002

McMahon, R., and Walsh, D. (2008). Efficient quiescent infection of normal human diploid fibroblasts with wild-type herpes simplex virus type 1. J Virol 82, 10218-10230. https://dx.doi.org/10.1128/JVI.00859-08

Merkl, P.E., Orzalli, M.H., and Knipe, D.M. (2018). Mechanisms of Host IFI16, PML, and Daxx Protein Restriction of Herpes Simplex Virus 1 Replication. J Virol 92. https://dx.doi.org/10.1128/JVI.00057-18

Metzler, D.W., and Wilcox, K.W. (1985). Isolation of herpes simplex virus regulatory protein ICP4 as a homodimeric complex. J Virol 55, 329-337

Misra, V., Walter, S., Yang, P., Hayes, S., and O'Hare, P. (1996). Conformational alteration of Oct-1 upon DNA binding dictates selectivity in differential interactions with related transcriptional coactivators. Mol Cell Biol $16,4404-4413$

Mohni, K.N., Dee, A.R., Smith, S., Schumacher, A.J., and Weller, S.K. (2013). Efficient herpes simplex virus 1 replication requires cellular ATR pathway proteins. J Virol 87, 531-542. https://dx.doi.org/10.1128/JVI.02504-12

Mohni, K.N., Livingston, C.M., Cortez, D., and Weller, S.K. (2010). ATR and ATRIP are recruited to herpes simplex virus type 1 replication compartments even though ATR signaling is disabled. J Virol 84, 12152-12164. https:// dx.doi.org/10.1128/JVI.01643-10

Mohni, K.N., Mastrocola, A.S., Bai, P., Weller, S.K., and Heinen, C.D. (2011). DNA mismatch repair proteins are required for efficient herpes simplex virus 1 replication. J Virol 85, 12241-12253. https://dx.doi.org/10.1128/JVI. 05487-11

Mou, F., Wills, E.G., Park, R., and Baines, J.D. (2008). Effects of lamin A/C, lamin B1, and viral US3 kinase activity on viral infectivity, virion egress, and the targeting of herpes simplex virus $\mathrm{U}(\mathrm{L}) 34$-encoded protein to the inner 
nuclear membrane. J Virol 82, 8094-8104. https://dx.doi.org/10.1128/JVI. 00874-08

Muller, S., and Dejean, A. (1999). Viral immediate-early proteins abrogate the modification by SUMO-1 of PML and Sp100 proteins, correlating with nuclear body disruption. J Virol 73, 5137-5143

Muller, S., Matunis, M.J., and Dejean, A. (1998). Conjugation with the ubiquitinrelated modifier SUMO-1 regulates the partitioning of PML within the nucleus. EMBO J 17, 61-70. https://dx.doi.org/10.1093/emboj/17.1.61

Muylaert, I., Tang, K.W., and Elias, P. (2011). Replication and recombination of herpes simplex virus DNA. J Biol Chem 286, 15619-15624. https://dx.doi.org/ 10.1074/jbc.R111.233981

Narayanan, A., Ruyechan, W.T., and Kristie, T.M. (2007). The coactivator host cell factor-1 mediates Set1 and MLL1 H3K4 trimethylation at herpesvirus immediate early promoters for initiation of infection. Proc Natl Acad Sci U S A 104, 10835-10840. https://dx.doi.org/10.1073/pnas.0704351104

Natarajan, R., Deshmane, S., Valyi-Nagy, T., Everett, R., and Fraser, N.W. (1991). A herpes simplex virus type 1 mutant lacking the ICPO introns reactivates with normal efficiency. J Virol 65, 5569-5573

O'Neill, F.J. (1977). Prolongation of herpes simplex virus latency in cultured human cells by temperature elevation. J Virol 24, 41-46

Oh, H.S., Bryant, K.F., Nieland, T.J., Mazumder, A., Bagul, M., Bathe, M., Root, D.E., and Knipe, D.M. (2014). A targeted RNA interference screen reveals novel epigenetic factors that regulate herpesviral gene expression. MBio 5, e01086-01013. https://dx.doi.org/10.1128/mBio.01086-13

Oh, J., and Fraser, N.W. (2008). Temporal association of the herpes simplex virus genome with histone proteins during a lytic infection. J Virol 82, 3530-3537. https://dx.doi.org/10.1128/JVI.00586-07

Ojala, P.M., Sodeik, B., Ebersold, M.W., Kutay, U., and Helenius, A. (2000). Herpes simplex virus type 1 entry into host cells: reconstitution of capsid binding and uncoating at the nuclear pore complex in vitro. Mol Cell Biol 20, 4922-4931

Ottosen, S., Herrera, F.J., Doroghazi, J.R., Hull, A., Mittal, S., Lane, W.S., and Triezenberg, S.J. (2006). Phosphorylation of the VP16 transcriptional 
activator protein during herpes simplex virus infection and mutational analysis of putative phosphorylation sites. Virology 345, 468-481. https:// dx.doi.org/10.1016/j.virol.2005.10.011

Parkinson, J., Lees-Miller, S.P., and Everett, R.D. (1999). Herpes simplex virus type 1 immediate-early protein vmw110 induces the proteasome-dependent degradation of the catalytic subunit of DNA-dependent protein kinase. J Virol $73,650-657$

Pasdeloup, D., Blondel, D., Isidro, A.L., and Rixon, F.J. (2009). Herpesvirus capsid association with the nuclear pore complex and viral DNA release involve the nucleoporin CAN/Nup214 and the capsid protein pUL25. J Virol 83, 6610-6623.JVI.02655-08 [pii] https://dx.doi.org/10.1128/JVI.02655-08

Perry, L.J., Rixon, F.J., Everett, R.D., Frame, M.C., and McGeoch, D.J. (1986). Characterization of the IE110 gene of herpes simplex virus type 1. J Gen Virol 67 ( Pt 11), 2365-2380. https://dx.doi.org/10.1099/0022-1317-67-11-2365

Phelan, A., Dunlop, J., Patel, A.H., Stow, N.D., and Clements, J.B. (1997). Nuclear sites of herpes simplex virus type 1 DNA replication and transcription colocalize at early times postinfection and are largely distinct from RNA processing factors. J Virol 71, 1124-1132

Pritchard, S.M., Cunha, C.W., and Nicola, A.V. (2013). Analysis of herpes simplex virion tegument ICP4 derived from infected cells and ICP4expressing cells. PLoS One 8, e70889. https://dx.doi.org/10.1371/ journal.pone.0070889

Quinlan, M.P., Chen, L.B., and Knipe, D.M. (1984). The intranuclear location of a herpes simplex virus DNA-binding protein is determined by the status of viral DNA replication. Cell 36, 857-868

Rai, T.S., Glass, M., Cole, J.J., Rather, M.I., Marsden, M., Neilson, M., Brock, C., Humphreys, I.R., Everett, R.D., and Adams, P.D. (2017). Histone chaperone HIRA deposits histone $\mathrm{H} 3.3$ onto foreign viral DNA and contributes to anti-viral intrinsic immunity. Nucleic Acids Res 45, 11673-11683. https://dx.doi.org/10.1093/nar/gkx771

Raja, P., Lee, J.S., Pan, D., Pesola, J.M., Coen, D.M., and Knipe, D.M. (2016). A Herpesviral Lytic Protein Regulates the Structure of Latent Viral Chromatin. MBio 7. https://dx.doi.org/10.1128/mBio.00633-16 
Ralph, M., Bednarchik, M., Tomer, E., Rafael, D., Zargarian, S., Gerlic, M., and Kobiler, O. (2017). Promoting Simultaneous Onset of Viral Gene Expression Among Cells Infected with Herpes Simplex Virus-1. Front Microbiol 8, 2152. https://dx.doi.org/10.3389/fmicb.2017.02152

Reyes, E.D., Kulej, K., Pancholi, N.J., Akhtar, L.N., Avgousti, D.C., Kim, E.T., Bricker, D.K., Spruce, L.A., Koniski, S.A., Seeholzer, S.H., et al. (2017). Identifying Host Factors Associated with DNA Replicated During Virus Infection. Mol Cell Proteomics 16, 2079-2097. https://dx.doi.org/10.1074/ mcp.M117.067116

Roizman, B., and Aurelian, L. (1965). Abortive Infection of Canine Cells by Herpes Simplex Virus. I. Characterization of Viral Progeny from Co-Operative Infection with Mutants Differing in Capacity to Multiply in Canine Cells. J Mol Biol 11, 528-538

Russell, J., and Preston, C.M. (1986). An in vitro latency system for herpes simplex virus type 2. J Gen Virol 67 ( Pt 2), 397-403. https://dx.doi.org/ 10.1099/0022-1317-67-2-397

Sacks, W.R., and Schaffer, P.A. (1987). Deletion mutants in the gene encoding the herpes simplex virus type 1 immediate-early protein ICPO exhibit impaired growth in cell culture. J Virol 61, 829-839

Samaniego, L.A., Neiderhiser, L., and DeLuca, N.A. (1998). Persistence and expression of the herpes simplex virus genome in the absence of immediateearly proteins. J Virol 72, 3307-3320

Scheck, A.C., Wigdahl, B., De Clercq, E., and Rapp, F. (1986). Prolonged herpes simplex virus latency in vitro after treatment of infected cells with acyclovir and human leukocyte interferon. Antimicrob Agents Chemother 29, 589-593

Sekine, E., Schmidt, N., Gaboriau, D., and O'Hare, P. (2017). Spatiotemporal dynamics of HSV genome nuclear entry and compaction state transitions using bioorthogonal chemistry and super-resolution microscopy. PLoS Pathog 13, e1006721. https://dx.doi.org/10.1371/journal.ppat.1006721

Sexton, T., and Cavalli, G. (2015). The role of chromosome domains in shaping the functional genome. Cell 160, 1049-1059. https://dx.doi.org/10.1016/j.cell. 2015.02.040 
Shapira, L., Ralph, M., Tomer, E., Cohen, S., and Kobiler, O. (2016). Histone Deacetylase Inhibitors Reduce the Number of Herpes Simplex Virus-1 Genomes Initiating Expression in Individual Cells. Front Microbiol 7, 1970. https://dx.doi.org/10.3389/fmicb.2016.01970

Sheldrick, P., Laithier, M., Lando, D., and Ryhiner, M.L. (1973). Infectious DNA from herpes simplex virus: infectivity of double-stranded and single-stranded molecules. Proc Natl Acad Sci U S A 70, 3621-3625

Shiraki, K., and Rapp, F. (1986). Establishment of herpes simplex virus latency in vitro with cycloheximide. J Gen Virol 67 ( Pt 11), 2497-2500. https:// dx.doi.org/10.1099/0022-1317-67-11-2497

Shivkumar, M., Lawler, C., Milho, R., and Stevenson, P.G. (2016). Herpes Simplex Virus 1 Interaction with Myeloid Cells In Vivo. J Virol 90, 8661-8672. https://dx.doi.org/10.1128/JVI.00881-16

Silva, L., Cliffe, A., Chang, L., and Knipe, D.M. (2008). Role for A-type lamins in herpesviral DNA targeting and heterochromatin modulation. PLoS Pathog 4, e1000071. https://dx.doi.org/10.1371/journal.ppat.1000071

Silva, L., Oh, H.S., Chang, L., Yan, Z., Triezenberg, S.J., and Knipe, D.M. (2012). Roles of the nuclear lamina in stable nuclear association and assembly of a herpesviral transactivator complex on viral immediate-early genes. MBio 3. https://dx.doi.org/10.1128/mBio.00300-11

Smiley, J.R., and Duncan, J. (1997). Truncation of the C-terminal acidic transcriptional activation domain of herpes simplex virus VP16 produces a phenotype similar to that of the in1814 linker insertion mutation. J Virol 71, 6191-6193

Smith, C.A., Bates, P., Rivera-Gonzalez, R., Gu, B., and DeLuca, N.A. (1993). ICP4, the major transcriptional regulatory protein of herpes simplex virus type 1, forms a tripartite complex with TATA-binding protein and TFIIB. J Virol 67, 4676-4687

Smith, S., Reuven, N., Mohni, K.N., Schumacher, A.J., and Weller, S.K. (2014). Structure of the herpes simplex virus 1 genome: manipulation of nicks and gaps can abrogate infectivity and alter the cellular DNA damage response. J Virol 88, 10146-10156. https://dx.doi.org/10.1128/JVI.01723-14 
Smith, S., and Weller, S.K. (2015). HSV-I and the cellular DNA damage response. Future Virol 10, 383-397. https://dx.doi.org/10.2217/fvl.15.18

Sourvinos, G., and Everett, R.D. (2002). Visualization of parental HSV-1 genomes and replication compartments in association with ND10 in live infected cells. EMBO J 21, 4989-4997

Stegen, C., Yakova, Y., Henaff, D., Nadjar, J., Duron, J., and Lippe, R. (2013). Analysis of virion-incorporated host proteins required for herpes simplex virus type 1 infection through a RNA interference screen. PLoS One 8, e53276. https://dx.doi.org/10.1371/journal.pone.0053276

Steiner, I., Spivack, J.G., Deshmane, S.L., Ace, C.I., Preston, C.M., and Fraser, N.W. (1990). A herpes simplex virus type 1 mutant containing a nontransinducing Vmw65 protein establishes latent infection in vivo in the absence of viral replication and reactivates efficiently from explanted trigeminal ganglia. J Virol 64, 1630-1638

Stern, S., Tanaka, M., and Herr, W. (1989). The Oct-1 homoeodomain directs formation of a multiprotein-DNA complex with the HSV transactivator VP16. Nature 341, 624-630. https://dx.doi.org/10.1038/341624a0

Sternsdorf, T., Jensen, K., and Will, H. (1997). Evidence for covalent modification of the nuclear dot-associated proteins PML and Sp100 by PIC1/ SUMO-1. J Cell Biol 139, 1621-1634

Stow, N.D., and Stow, E.C. (1986). Isolation and characterization of a herpes simplex virus type 1 mutant containing a deletion within the gene encoding the immediate early polypeptide Vmw110. J Gen Virol 67 ( Pt 12), 2571-2585. https://dx.doi.org/10.1099/0022-1317-67-12-2571

Suk, H., and Knipe, D.M. (2015). Proteomic analysis of the herpes simplex virus 1 virion protein 16 transactivator protein in infected cells. Proteomics 15, 1957-1967. https://dx.doi.org/10.1002/pmic.201500020

Suzich, J.B., and Cliffe, A.R. (2018). Strength in diversity: Understanding the pathways to herpes simplex virus reactivation. Virology 522, 81-91. https:// dx.doi.org/10.1016/j.virol.2018.07.011

Taylor, M.P., Kobiler, O., and Enquist, L.W. (2012). Alphaherpesvirus axon-tocell spread involves limited virion transmission. Proc Natl Acad Sci U S A 109, 17046-17051. https://dx.doi.org/10.1073/pnas.1212926109 
Taylor, T.J., and Knipe, D.M. (2004). Proteomics of herpes simplex virus replication compartments: association of cellular DNA replication, repair, recombination, and chromatin remodeling proteins with ICP8. J Virol 78, 5856-5866. https://dx.doi.org/10.1128/JVI.78.11.5856-5866.2004

Tomer, E., Cohen, E.M., Drayman, N., Afriat, A., Weitzman, M.D., Zaritsky, A., and Kobiler, O. (2019). Coalescing replication compartments provide the opportunity for recombination between coinfecting herpesviruses. FASEB $\mathrm{J}$ 33, 9388-9403. https://dx.doi.org/10.1096/fj.201900032R

Trigg, B.J., and Ferguson, B.J. (2015). Functions of DNA damage machinery in the innate immune response to DNA virus infection. Curr Opin Virol 15, 56-62. https://dx.doi.org/10.1016/j.coviro.2015.08.001

Trigg, B.J., Lauer, K.B., Fernandes Dos Santos, P., Coleman, H., Balmus, G., Mansur, D.S., and Ferguson, B.J. (2017). The Non-Homologous End Joining Protein PAXX Acts to Restrict HSV-1 Infection. Viruses 9. https://dx.doi.org/ 10.3390/v9110342

Tunnicliffe, R.B., Lockhart-Cairns, M.P., Levy, C., Mould, A.P., Jowitt, T.A., Sito, H., Baldock, C., Sandri-Goldin, R.M., and Golovanov, A.P. (2017). The herpes viral transcription factor ICP4 forms a novel DNA recognition complex. Nucleic Acids Res 45, 8064-8078. https://dx.doi.org/10.1093/nar/gkx419 van Lint, A.L., Murawski, M.R., Goodbody, R.E., Severa, M., Fitzgerald, K.A., Finberg, R.W., Knipe, D.M., and Kurt-Jones, E.A. (2010). Herpes simplex virus immediate-early ICPO protein inhibits Toll-like receptor 2-dependent inflammatory responses and NF-kappaB signaling. J Virol 84, 10802-10811. https://dx.doi.org/10.1128/JVI.00063-10

Wadsworth, S., Jacob, R.J., and Roizman, B. (1975). Anatomy of herpes simplex virus DNA. II. Size, composition, and arrangement of inverted terminal repetitions. J Virol 15, 1487-1497

Waisner, H., and Kalamvoki, M. (2019). The ICPO Protein of Herpes Simplex Virus 1 (HSV-1) Downregulates Major Autophagy Adaptor Proteins Sequestosome 1 and Optineurin during the Early Stages of HSV-1 Infection. J Virol 93. https://dx.doi.org/10.1128/JVI.01258-19

Wang, Q.Y., Zhou, C., Johnson, K.E., Colgrove, R.C., Coen, D.M., and Knipe, D.M. (2005). Herpesviral latency-associated transcript gene promotes 
assembly of heterochromatin on viral lytic-gene promoters in latent infection. Proc Natl Acad Sci U S A 102, 16055-16059. https://dx.doi.org/10.1073/pnas. 0505850102

Wang, X., Diao, C., Yang, X., Yang, Z., Liu, M., Li, X., and Tang, H. (2016). ICP4-induced miR-101 attenuates HSV-1 replication. Sci Rep 6, 23205. https://dx.doi.org/10.1038/srep23205

Weinheimer, S.P., Boyd, B.A., Durham, S.K., Resnick, J.L., and O'Boyle, D.R., 2nd (1992). Deletion of the VP16 open reading frame of herpes simplex virus type 1. J Virol 66, 258-269

Wilkinson, D.E., and Weller, S.K. (2003). The role of DNA recombination in herpes simplex virus DNA replication. IUBMB Life 55, 451-458. https:// dx.doi.org/10.1080/15216540310001612237

Wu, C.A., Nelson, N.J., McGeoch, D.J., and Challberg, M.D. (1988). Identification of herpes simplex virus type 1 genes required for origindependent DNA synthesis. J Virol 62, 435-443

Wyler, E., Franke, V., Menegatti, J., Kocks, C., Boltengagen, A., Praktiknjo, S., Walch-Ruckheim, B., Bosse, J., Rajewsky, N., Grasser, F., et al. (2019). Single-cell RNA-sequencing of herpes simplex virus 1-infected cells connects NRF2 activation to an antiviral program. Nat Commun 10, 4878. https:// dx.doi.org/10.1038/s41467-019-12894-z

Wysocka, J., and Herr, W. (2003). The herpes simplex virus VP16-induced complex: the makings of a regulatory switch. Trends Biochem Sci 28, 294-304. https://dx.doi.org/10.1016/S0968-0004(03)00088-4

Xu, P., Mallon, S., and Roizman, B. (2016). PML plays both inimical and beneficial roles in HSV-1 replication. Proc Natl Acad Sci U S A 113, E3022-3028. https://dx.doi.org/10.1073/pnas.1605513113

Xu, P., and Roizman, B. (2017). The SP100 component of ND10 enhances accumulation of PML and suppresses replication and the assembly of HSV replication compartments. Proc Natl Acad Sci U S A 114, E3823-E3829. https://dx.doi.org/10.1073/pnas.1703395114

Yao, F., and Courtney, R.J. (1989). A major transcriptional regulatory protein (ICP4) of herpes simplex virus type 1 is associated with purified virions. J Virol 63, 3338-3344 
Yao, F., and Courtney, R.J. (1992). Association of ICP0 but not ICP27 with purified virions of herpes simplex virus type 1. J Virol 66, 2709-2716

You, A., Tong, J.K., Grozinger, C.M., and Schreiber, S.L. (2001). CoREST is an integral component of the CoREST- human histone deacetylase complex. Proc Natl Acad Sci U S A 98, 1454-1458. https://dx.doi.org/10.1073/pnas. 98.4.1454

Zargar, Z., and Tyagi, S. (2012). Role of host cell factor-1 in cell cycle regulation. Transcription 3, 187-192. https://dx.doi.org/10.4161/trns.20711 
